\title{
Global analysis of seasonality in the shell flux of extant planktonic Foraminifera
}

\author{
L. Jonkers ${ }^{1}$ and M. Kučera ${ }^{2}$ \\ ${ }^{1}$ School of Earth and Ocean Sciences, Cardiff University, Main building, Park Place, Cardiff, CF10 3AT, Wales, UK \\ ${ }^{2}$ MARUM \& Fachbereich Geowissenschaften, Universität Bremen, Leobener Strasse, 28359 Bremen, Germany \\ Correspondence to: L. Jonkers (jonkersl@ cardiff.ac.uk)
}

Received: 5 November 2014 - Published in Biogeosciences Discuss.: 21 January 2015

Revised: 19 March 2015 - Accepted: 22 March 2015 - Published: 15 April 2015

\begin{abstract}
Shell fluxes of planktonic Foraminifera species vary intra-annually in a pattern that appears to follow the seasonal cycle. However, the variation in the timing and prominence of seasonal flux maxima in space and among species remains poorly constrained. Thus, although changing seasonality may result in a flux-weighted temperature offset of more than $5^{\circ} \mathrm{C}$ within a species, this effect is often ignored in the interpretation of Foraminifera-based paleoceanographic records. To address this issue we present an analysis of the intra-annual pattern of shell flux variability in 37 globally distributed time series. The existence of a seasonal component in flux variability was objectively characterised using periodic regression. This analysis yielded estimates of the number, timing and prominence of seasonal flux maxima. Over $80 \%$ of the flux series across all species showed a statistically significant periodic component, indicating that a considerable part of the intra-annual flux variability is predictable. Temperature appears to be a powerful predictor of flux seasonality, but its effect differs among species. Three different modes of seasonality are distinguishable. Tropical and subtropical species (Globigerinoides ruber (white and pink varieties), Neogloboquadrina dutertrei, Globigerinoides sacculifer, Orbulina universa, Globigerinella siphonifera, Pulleniatina obliquiloculata, Globorotalia menardii, Globoturborotalita rubescens, Globoturborotalita tenella and Globigerinoides conglobatus) appear to have a less predictable flux pattern, with random peak timing in warm waters. In colder waters, seasonality is more prevalent: peak fluxes occur shortly after summer temperature maxima and peak prominence increases. This tendency is stronger in species with a narrower temperature range, implying that warm-adapted species find it increas-
\end{abstract}

ingly difficult to reproduce outside their optimum temperature range and that, with decreasing mean temperature, their flux is progressively more focussed in the warm season. The second group includes the temperate to cold-water species Globigerina bulloides, Globigerinita glutinata, Turborotalita quinqueloba, Neogloboquadrina incompta, Neogloboquadrina pachyderma, Globorotalia scitula, Globigerinella calida, Globigerina falconensis, Globorotalia theyeri and Globigerinita uvula. These species show a highly predictable seasonal pattern, with one to two peaks a year, which occur earlier in warmer waters. Peak prominence in this group is independent of temperature. The earlier-when-warmer pattern in this group is related to the timing of productivity maxima. Finally, the deep-dwelling Globorotalia truncatulinoides and Globorotalia inflata show a regular and pronounced peak in winter and spring. The remarkably low flux outside the main pulse may indicate a long reproductive cycle of these species. Overall, our analysis indicates that the seasonality of planktonic Foraminifera shell flux is predictable and reveals the existence of distinct modes of phenology among species. We evaluate the effect of changing seasonality on paleoceanographic reconstructions and find that, irrespective of the seasonality mode, the actual magnitude of environmental change will be underestimated. The observed constraints on flux seasonality can serve as the basis for predictive modelling of flux pattern. As long as the diversity of species seasonality is accounted for in such models, the results can be used to improve reconstructions of the magnitude of environmental change in paleoceanographic records. 


\section{Introduction}

Planktonic Foraminifera are unicellular marine zooplankton with a global distribution. About 40 extant morphospecies are known and a number of these are symbiont-bearing (Hemleben et al., 1989). Planktonic Foraminifera build a calcite shell, which rapidly sinks after the death of the organism (Takahashi and Bé, 1984). Above the carbonate compensation depth, these shells are well preserved and may form an important part of the sediment. As a result, planktonic Foraminifera play a significant role in the marine carbonate cycle (Schiebel, 2002) and their fossil record is an important source of information on the physical and chemical conditions of past oceans. However, the interpretation of Foraminifera-based proxies of past environmental change is not straightforward and requires detailed knowledge on the ecology of the species involved.

The abundance of planktonic Foraminifera and the export flux of their shells vary both spatially and temporally (e.g. Bé, 1960; Bé and Tolderlund, 1971; Deuser et al., 1981). Timescales of temporal variability range from less than 1 month (lunar) to seasonal and interannual scales and beyond (e.g. Deuser et al., 1981; Marchant et al., 2004; Spindler et al., 1979). The intra-annual variability can range over several orders of magnitude (Deuser et al., 1981; Tolderlund and Bé, 1971) and because it resonates with the seasonal cycle of environmental conditions, it has a particularly large potential to modify the proxy signal recorded in a fossil assemblage. For example, apart from in the tropics, the seasonal sea surface temperature variability is always greater than the interannual variability (Mackas et al., 2012). Hence, a thorough understanding of the seasonal cycle in planktonic Foraminifera is essential to improve our ability to reconstruct past ocean changes.

Like in other groups of marine plankton, seasonality in planktonic Foraminifera can in principle manifest itself in two ways: (i) through changes in the timing of the peak flux or peak abundance and (ii) through changes in the amplitude of the seasonal cycle. Both aspects of seasonality could affect planktonic Foraminifera proxies, leading to seasonal biases in the variables recorded by fossil assemblages. In the case of temperature reconstructions, this can lead to offsets from mean conditions by several degrees (e.g. Fraile et al., 2009a; Jonkers et al., 2010). Differences in the seasonal pattern of shell flux among species have been exploited to reconstruct variations in seasonal temperatures (Saher et al., 2007). In addition, seasonality is thought to explain part of the difference between proxies that are Foraminifera-based and other proxies (Laepple and Huybers, 2013; Leduc et al., 2010).

Besides being species-specific (Deuser et al., 1981), seasonality in planktonic Foraminifera fluxes also varies spatially within individual species (Tolderlund and Bé, 1971), implying that the seasonal cycle is under environmental control. Consequently, seasonality may have changed as a function of climate and/or oceanic change through time. Until now, few studies have investigated the effect of such transient changes in seasonality on foraminiferal records. Using a Foraminifera model coupled to global simulations with an ecosystem model, Fraile et al. (2009b) have shown that the timing of the maximum production of Foraminifera species could have shifted by as much as 6 months between the last glacial maximum and the present day, but explicit efforts to quantify seasonal bias in planktonic foraminiferal proxies remain challenging (Schneider et al., 2010).

In most sediment trap studies, the recurrence time of the flux peaks is linked to the seasonal pattern of temperature (Zaric et al., 2005). Clearly, as with other zooplankton (Mackas et al., 2012; Richardson, 2008), temperature appears to be an important factor controlling the phenology of planktonic Foraminifera. However, several other parameters, some(times) correlated with temperature, such as food availability, nutrient availability, predation, competition, light availability and salinity have also been suggested to be important controls, particularly within the optimum temperature range of a species (Hemleben et al., 1989; Northcote and Neil, 2005; Ortiz and Mix, 1992; Ortiz et al., 1995). Until now there has been no effort to assess flux seasonality in sediment trap records on a global scale. Instead of an evaluation of observational data, recent investigations of seasonality in planktonic Foraminifera were based on models (Fraile et al., 2008; Lombard et al., 2011; Zaric et al., 2006). Despite the different approaches, these models provided a reasonable first-order description of the seasonality in planktonic Foraminifera. However, our incomplete understanding of the mechanisms that control seasonality hampers further improvements and validation of these models and prevents accounting for seasonality effects on paleorecords. This is in part due to the lack of a global overview of foraminiferal seasonality.

Here we present such a synthesis based on a large number of sediment trap time series from across the world oceans. Sediment traps provide continuous time series of settling shell fluxes, typically at a resolution of less than 1 month, and are therefore ideal for studying phenology. Importantly, shell fluxes represent the settling of dead Foraminifera and are strictly speaking not directly related to the abundance of Foraminifera in the water column. However, only a limited number of repeated plankton net surveys, which are needed to assess seasonal water column abundance, exist (Field, 2004; Schiebel et al., 1997), and these are often of too low a resolution and duration to assess seasonality. We therefore assess phenology from the settling fluxes, which are, given the short life span of Foraminifera (Hemleben et al., 1989), likely to be strongly linked to abundance. Our aim is to determine the extent of the seasonal component in the flux data and evaluate its predictability. 


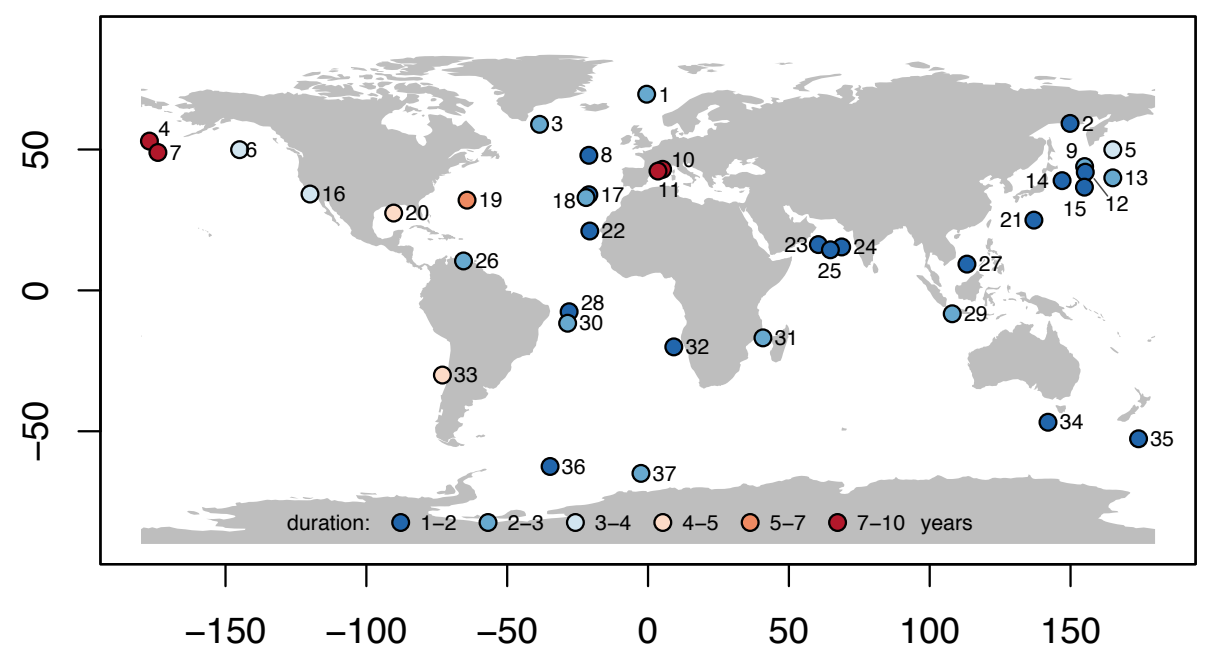

Figure 1. Distribution and duration of sediment trap time series used in this study. Site numbers refer to Table 1.

\section{Data and methods}

To analyse the seasonality of planktonic Foraminifera shell flux, we produced a compilation of globally distributed moored sediment trap time series with a duration of at least 1 year. Traps close to the sea floor or in the vicinity of (steep) topography that showed the influence of resuspended material (for instance, the presence of benthic Foraminifera) were not considered. In cases were multiple sediment traps were deployed at different depths on the same mooring, we report data from the shallowest trap as this (likely) reduces the catchment area of the trap and the data hence reflect local conditions more closely. The complete data set contains 37 time series (Table 1). The sites are unevenly distributed globally, with the majority (28) from the Northern Hemisphere and an important cluster of 8 traps in the northwest Pacific (Fig. 1). Nevertheless, the data span a temperature range of almost $30^{\circ} \mathrm{C}$ without large gaps. Trap depths varied between 250 and $5000 \mathrm{~m}$ (Table 1), and several sites are close to the continents, but only a single sediment trap was deployed at a location with a water depth of less than $1 \mathrm{~km}$. We therefore consider the sites to reflect pelagic settings. The average duration of the time series is 2.75 years, and the longer ones are predominantly from the Northern Hemisphere (Fig. 1). The mean length of the collection interval was 19 days but varied between 4 days and 1 month (Fig. 2a). Collection intervals were often also variable during the deployments. Most studies reported fluxes of shells of more than 125 or $150 \mu \mathrm{m}$; four used narrower size ranges (Table 1). We report here on 23 species for which counts in five or more time series are available (Table 2). The taxonomy in all time series has been harmonised such that the Neogloboquadrina pachyderma (rightcoiling) is considered as a separate species and referred to as Neogloboquadrina incompta, Globigerinella aequilateralis is referred to as Globigerinella siphonifera, and Globigerinoides trilobus and G. quadrilobatus are included in Glo- bigerinoides sacculifer. In addition Globigerina umbilicata is considered synonymous with $G$. bulloides. Since very few studies reported coiling direction in Globorotalia truncatulinoides, no distinction was made between left- and rightcoiling varieties of this species. Additional remarks specific to individual time series are included in Table 1.

To link the observed shell flux patterns to environmental conditions, temperature and productivity data were extracted for the positions of all traps. Temperature has been considered because it is known to play a key role in the phenology of other zooplankton (Mackas et al., 2012; Richardson, 2008). Most of the other parameters suggested as influencing the phenology of planktonic Foraminifera, such as light, mixed layer depth and nutrient availability, only affect their seasonality indirectly by affecting the phytoplankton, a major food source for many planktonic foraminiferal species. This results in a predictable phase relationship, with zooplankton always lagging behind phytoplankton. Thus, the inclusion of temperature and productivity should allow us to study both end-member scenarios, with Foraminifera responding exclusively to temperature or following productivity. Because continuous observations of near surface conditions from the moorings are not available, temperature data for the upper water column $(0-50 \mathrm{~m})$ were taken from the 2009 World Ocean Atlas (Locarnini et al., 2010). Using climatology data also allows us to use upper-ocean temperatures that are more representative of Foraminifera habitat than surface temperatures derived from remote sensing. Moreover, interannual temperature variability at individual sites is typically small (often less than $1^{\circ} \mathrm{C}$ ) compared to the temperature differences between sites $\left(\sim 30^{\circ} \mathrm{C}\right)$, warranting the use of climatology data since our objective is to compare the patterns among sites. We use sea surface chlorophyll $a$ concentration data as an indicator of upper-ocean productivity. Since a large part of the shell flux time series predates the era of satellite 
Table 1. Details of shell flux time series used in this study. Site numbers refer to Fig. 1.

\begin{tabular}{|c|c|c|c|c|c|c|c|}
\hline Site no. & Lat $\left({ }^{\circ} \mathrm{N}\right)$ & Long $\left({ }^{\circ} \mathrm{E}\right)$ & Deployment depth (m) & Duration (days) & Size $(\mu \mathrm{m})$ & Remarks & References \\
\hline 1 & 69.7 & -0.5 & 500 & 780 & $63-500$ & & Jensen, 1998 \\
\hline 2 & 59.3 & 149.8 & 258 & 365 & $>150$ & $N$. dutertrei removed & Alderman, 1996 \\
\hline 3 & 59.0 & -38.5 & 2750 & 988 & $150-315$ & $\begin{array}{l}\text { T. quinqueloba } \\
150-250 u \mathrm{~m}\end{array}$ & $\begin{array}{l}\text { Jonkers et al., 2010, } \\
2013\end{array}$ \\
\hline 4 & 53.1 & -177.0 & 3198 & 2926 & $>125$ & & Asahi and Takahashi, 2007 \\
\hline 5 & 50.0 & 165.0 & 3260 & 1141 & $>125$ & & Kuroyanagi et al., 2002 \\
\hline 6 & 50.0 & -145.0 & 3800 & 1128 & $>125$ & & Sautter and Thunell, 1989 \\
\hline 7 & 49.0 & -174.0 & 4812 & 2803 & $>125$ & & Asahi and Takahashi, 2007 \\
\hline 8 & 48.0 & -21.0 & $2000-3700$ & 378 & $>150$ & Depth change & Wolfteich, 1994 \\
\hline 9 & 44.0 & 155.0 & 2957 & 851 & $>125$ & & Kuroyanagi et al., 2002 \\
\hline 10 & 43.0 & 5.2 & 500 & 3338 & $>150$ & & Rigual-Hernández et al., 2012 \\
\hline 11 & 42.4 & 3.5 & 500 & 3552 & $>150$ & & Rigual-Hernández et al., 2012 \\
\hline 12 & 42.0 & 155.2 & 1091 & 380 & $>125$ & & Mohiuddin et al., 2005 \\
\hline 13 & 40.0 & 165.0 & 2986 & 768 & $>125$ & & Kuroyanagi et al., 2002 \\
\hline 14 & 39.0 & 147.0 & $1371-1586$ & 608 & $>125$ & Depth change & Mohiuddin et al., 2002 \\
\hline 15 & 36.7 & 154.9 & 5034 & 376 & $>125$ & & Mohiuddin et al., 2004 \\
\hline 16 & 34.3 & -120.0 & $590 ; 470$ & 1108 & $>125$ & Depth change & $\begin{array}{l}\text { Darling et al., 2003; } \\
\text { Kincaid et al., } 2000\end{array}$ \\
\hline 17 & 34.0 & -21.0 & 2000 & 378 & $>150$ & & Wolfteich, 1994 \\
\hline 18 & 33.0 & 22.0 & 3000 & 764 & $>125$ & & Storz et al., 2009 \\
\hline 19 & 32.1 & -64.3 & 3200 & 1848 & $>125$ & & $\begin{array}{l}\text { Deuser and Ross, 1989; } \\
\text { Deuser et al., } 1981\end{array}$ \\
\hline 20 & 27.5 & -90.3 & 700 & 1563 & $>150$ & & $\begin{array}{l}\text { Poore et al., 2013; } \\
\text { Reynolds et al., } 2013\end{array}$ \\
\hline 21 & 25.0 & 137.0 & $917-1388$ & 573 & $>125$ & Depth change & Mohiuddin et al., 2002 \\
\hline 22 & 21.2 & -20.7 & 3500 & 718 & $>150$ & & $\begin{array}{l}\text { Fischer et al., 1996; } \\
\text { Zaric et al., } 2005\end{array}$ \\
\hline 23 & 16.3 & 60.5 & 3020 & 508 & $>125$ & & Curry et al., 1992 \\
\hline 24 & 15.5 & 68.8 & 2790 & 482 & $>125$ & & Curry et al., 1992 \\
\hline 25 & 14.5 & 64.8 & 732 & 486 & $>125$ & & Curry et al., 1992 \\
\hline 26 & 10.5 & -65.5 & Not reported & 1002 & $>125$ & & Tedesco and Thunell, 2003 \\
\hline 27 & 9.4 & 113.2 & 720 & 662 & $>154$ & & Wan et al., 2010 \\
\hline 28 & -7.5 & -28.0 & 671 & 500 & $>150$ & & Zaric et al., 2005 \\
\hline 29 & -8.3 & 108.0 & $1370-1860$ & 963 & $>150$ & Depth change & Mohtadi et al., 2009 \\
\hline 30 & -11.6 & -28.5 & 710 & 944 & $>150$ & & Zaric et al., 2005 \\
\hline 31 & -16.8 & 40.8 & 2250 & 863 & $250-315$ & & Fallet et al., 2010, 2011 \\
\hline 32 & -20.0 & 9.2 & 1648 & 524 & $>150$ & & Zaric et al., 2005 \\
\hline 33 & -30.0 & -73.0 & $2300-2500$ & 1563 & $>150$ & & Marchant et al., 2004, 1998 \\
\hline 34 & -46.8 & 142.0 & 3800 & 464 & $>150$ & & King and Howard, 2003 \\
\hline 35 & -52.6 & 174.2 & $442 ; 362$ & 410 & $>150$ & Depth change & Northcote and Neil, 2005 \\
\hline 36 & -62.5 & -34.8 & 863 & 418 & $>125$ & & Donner and Wefer, 1994 \\
\hline 37 & -64.9 & -2.5 & 360 & 745 & $>125$ & & Donner and Wefer, 1994 \\
\hline
\end{tabular}
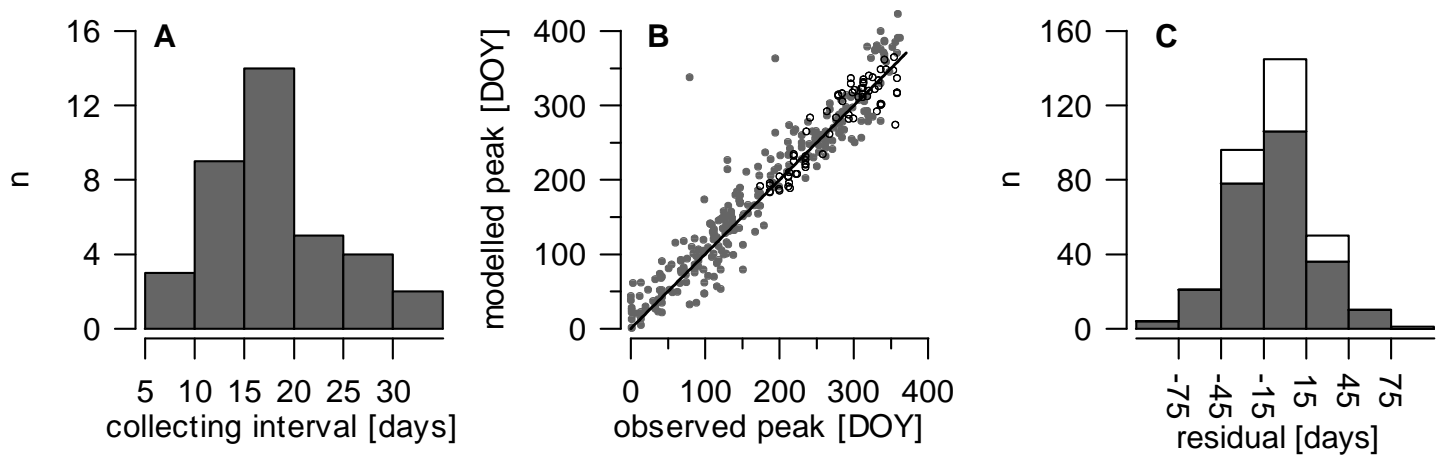

Figure 2. Histogram of average collecting interval for all time series (a). Observed vs. modelled peak time (b) and residual of observed-modelled peak time (c). See Figs. S3 and S4 for individual species. Solid symbols in (b) and grey shading in (c) denote single or first cycles and open symbols second cycles in panel (c). 
observations, we use SeaWiFS (Sea-viewing Wide Field-ofview Sensor) monthly climatology (data downloaded from http://oceancolor.gsfc.nasa.gov/). This means that interannual productivity variability is ignored, but, similarly to temperature, the interannual range in peak productivity timing at an individual site ( $\sim 1$ month) is small compared the total range (12 months) considered here.

To objectively characterise the pattern of the seasonal shell flux, we have used periodic regression, a simple method that is suited for cyclic data at low and variable resolutions, irregular starting points and with short duration (Batchelet, 1981; deBruyn and Meeuwig, 2001; Mackas et al., 2012). In addition to an objective test for the presence of systematic time-related irregularity in flux, it can detect the number of peaks (assuming these occur at harmonics of the yearly cycle) and objectively describes the magnitude of the peak flux. The method has been used extensively to describe cyclic phenomena in biology (Bell et al., 2001; deBruyn and Meeuwig, 2001; Drolet and Barbeau, 2009). Figure 3 illustrates the approach using an example of Turborotalia quinqueloba from the Irminger Sea.

Prior to analysis, zero fluxes were replaced with half of the observed minimum flux and the data were converted to a $\log _{10}$ scale. All observations were put on the same timescale by converting the middate of the collection intervals to year days, which were subsequently angular-transformed using DOY/365.25 $\times 2 \pi$ (DOY stands for "day of the year"). No attempt was made to correct for settling time and/or delay due to production.

Using linear multiple regression we tested for the presence of one or two cycles per year in the shell flux by fitting two different models to the observations:

$J(t)=A+B \sin (t)+C \cos (t)$

and

$J(t)=A+D \sin (2 t)+E \cos (2 t)$,

where $J(t)$ is the shell flux at time $t$ and $A-E$ are the parameters to be estimated. This approach yields a robust estimate of the mean - the periodic mean, parameter $A$ in the equations above - as well as the amplitude and phase angle or peak timing of the shell flux. The significance of the models was evaluated using ANOVA for multiple regression. Only model fits that pass this test with $95 \%$ confidence were considered, and if both one- and two-cycle models were significant, then the model that explained more variance (highest adjusted $r^{2}$ ) was chosen. Implicit to this approach are two important assumptions: (i) the seasonal shell flux follows a sinusoidal (i.e. symmetric) pattern and (ii) in the case of a model with two cycles per year, there is a $365.25 / 2$ days spacing between the two peaks. Both assumptions are reasonable given the ecology of Foraminifera and the nature of the data, but to confirm the appropriateness of the method, we have evaluated how well peak timing is estimated.
To enable a comparison of peak timing from different hemispheres, dates from sites in the Southern Hemisphere were transformed to Northern Hemisphere equivalents by adding or subtracting 182.5 days. For a similar reason, the comparison of flux amplitude was facilitated by normalising the log-transformed amplitude of peak flux to the periodic mean:

$\mathrm{PP}=\log \left(\frac{10^{\text {amplitude }}}{10^{\text {per.mean }}}\right)$.

Expressed in this way, a peak prominence (PP) of 1 describes a situation where the peak flux is 10 times larger than the annual mean flux, whereas a value of -1 describes a time series where the flux during the maximum is only elevated by $10 \%$ above the annual mean. All calculations were carried out using R (R core team, 2013), and maps were generated using package mapplots (Gerritsen, 2012).

\section{Results}

The 37 globally distributed time series reveal the presence of large variability in the partitioning of shell flux to seasons (Fig. S1 in the Supplement). Large variation in seasonality among species, but importantly also within the same species at different locations, is evident. Considerable differences exist between sites close together, but some coherent patterns appear. Trends towards a peak later in the year or in summer at higher latitudes are visible in some species (e.g. $G$. bulloides and $N$. incompta). Interestingly, seasonally varying fluxes do not appear to be exclusive to the extratropics.

\subsection{Evaluating periodic regression}

The time series in the database have different and often varying resolutions and durations. In addition, many time series have gaps due to failing sediment trap rotation or unsuccessful deployments. These factors render an objective characterisation of the seasonal cycle challenging, and we therefore apply the method of periodic regression. Given the assumptions underlying the periodic regression approach, we first evaluate the appropriateness of the method to describe the seasonal shell flux cycles. To this end, we test how well peak timing is estimated using three species from the longest time series available (Gulf of Lions, site 11, Table 1). This time series is 10 years long, and the observed interannual variability in the peak timing (expressed as the midpoint date of the sampling interval with highest flux) for the three species is 15 to 38 days. This is comparable to the average difference between observed peak time and the peak time estimated by periodic regression for each year separately (21 to 36 days). The difference between the observed and modelled timing of peak flux reflects aliasing due to the resolution of the discrete sampling and the assumption that the flux pattern has a sinusoidal shape. The fact that the observed interannual variabil- 
Table 2. Results from periodic regression. Species marked with an * have fewer than five observations with significant cyclicity and are excluded from the analysis.

\begin{tabular}{|c|c|c|c|c|c|c|c|c|}
\hline Species & No. in Fig. 6 & No. of time series & 1 cycle & 2 cycle & 1 cycle $(\%)$ & 2 cycle $(\%)$ & mean PP & PP' $\left({ }^{\circ} \mathrm{C}^{-1}\right)$ \\
\hline \multicolumn{9}{|l|}{ Group A } \\
\hline G. ruber (white) & 1 & 20 & 12 & 5 & 60 & 25 & -0.91 & -0.09 \\
\hline N. dutertrei & 2 & 17 & 13 & 3 & 76 & 18 & -0.36 & -0.03 \\
\hline G. sacculifer & 3 & 18 & 11 & 4 & 61 & 22 & -0.64 & -0.07 \\
\hline O. universa & 4 & 18 & 10 & 2 & 56 & 11 & -0.05 & -0.06 \\
\hline G. siphonifera & 5 & 17 & 4 & 4 & 24 & 24 & -0.40 & -0.06 \\
\hline G. ruber (pink) & 6 & 8 & 5 & 2 & 63 & 25 & -0.07 & -0.14 \\
\hline P. obliquiloculata & 7 & 8 & 3 & 4 & 38 & 50 & 0.00 & -0.48 \\
\hline G. menardii & 8 & 6 & 2 & 3 & 33 & 50 & -0.74 & -0.21 \\
\hline G. rubescens & 9 & 6 & 3 & 2 & 50 & 33 & -0.41 & -0.17 \\
\hline G. tenella* & - & 7 & 2 & 2 & 29 & 29 & - & - \\
\hline G. conglobatus* & - & 5 & 1 & 1 & 20 & 20 & - & - \\
\hline \multicolumn{9}{|l|}{ Group B } \\
\hline G. bulloides & 10 & 32 & 22 & 9 & 69 & 28 & -0.86 & 0.02 \\
\hline G. glutinata & 11 & 25 & 13 & 8 & 52 & 32 & -0.93 & -0.01 \\
\hline T. quinqueloba & 12 & 21 & 15 & 5 & 71 & 24 & -0.94 & 0.01 \\
\hline N. incompta & 13 & 22 & 12 & 5 & 55 & 23 & -0.76 & 0.01 \\
\hline N. pachyderma & 14 & 16 & 11 & 4 & 69 & 25 & -0.91 & 0.00 \\
\hline G. scitula & 15 & 18 & 10 & 2 & 56 & 11 & -0.30 & 0.02 \\
\hline G. calida & 16 & 9 & 4 & 3 & 44 & 33 & -0.82 & 0.02 \\
\hline G. falconensis & 17 & 6 & 4 & 2 & 67 & 33 & 0.14 & 0.01 \\
\hline G. theyeri* & - & 5 & 2 & 2 & 40 & 40 & - & - \\
\hline G. uvula* & - & 5 & 4 & 0 & 80 & 0 & - & - \\
\hline \multicolumn{9}{|l|}{ Group C } \\
\hline G. inflata & 18 & 13 & 10 & 1 & 77 & 8 & 0.15 & 0.08 \\
\hline \multirow[t]{5}{*}{ G. truncatulinoides } & 19 & 12 & 9 & 0 & 75 & 0 & -0.02 & 0.09 \\
\hline & \multicolumn{8}{|c|}{ Group average } \\
\hline & & & & A & 51 & 29 & -0.40 & -0.14 \\
\hline & & & & B & 60 & 26 & -0.67 & 0.01 \\
\hline & & & & $\mathrm{C}$ & 76 & 4 & 0.07 & 0.08 \\
\hline
\end{tabular}
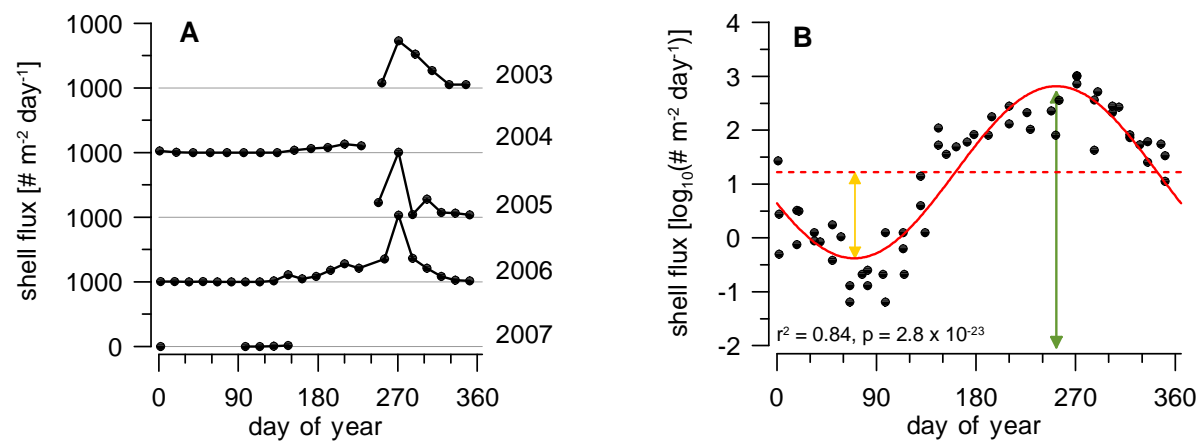

Figure 3. Example of the periodic regression approach. (a) Raw data plotted vs. year day and at middates of collection intervals. (b) Logtransformed data and fitting approach; the thick red line represents the best fit for the two models tested. The dashed horizontal red line is the periodic mean, the yellow arrow indicates the amplitude of the cycle and the green arrow indicates the modelled peak time. Data are from $T$. quinqueloba from site 3 . 
ity in peak timing is similar to the precision of the periodic regression puts important constraints on the method, implying that interannual variability in the peak timing (within approximately 1 month) cannot be resolved.

Considering that the average resolution of the trap series is 19 days, interannual variability in peak timing of the same type as observed in the Gulf of Lions series could only be detected in less than half of the series covering more than 1 year. This would limit the analysis at the cost of generalisation. We thus decided to ignore the interannual component of the variability and use annual composites of the entire time series for further analyses. This ensures that all data sets, irrespective of their duration and resolution, are treated uniformly. In multiyear series, such analysis also alleviates the problem of uneven sampling and allows the use of all data despite sampling gaps.

The sinusoidal representation of the seasonal shell flux pattern imposed by the periodic regression describes the variance in the annual composite data to varying degrees (see Fig. S2 for all fitting results). The maximum adjusted coefficient of determination for the periodic regression is 0.88 ( $G$. bulloides at site 3), and the minimum coefficient still considered significant is 0.03 (Globigerinita uvula at site 33). On average, the periodic regression model explains more than one third of the variance, confirming that most of the flux series have a substantial periodic seasonal component. Irrespective of the regression coefficient, the difference between observed and estimated peak timing is small (mean error: -7 days; Figs. 2 and S3 for individual species), with most of the differences being within the average resolution of the time series. Nevertheless, there seems to be a tendency by the periodic regression to overestimate the timing of the peak (Fig. 2). Although the amount is below the resolution of most time series, this small bias may reflect an asymmetry in the peak flux pattern with higher fluxes following but not preceding the peak.

With respect to the amplitude of the seasonal signal, the amplitude estimated by the periodic regression is always smaller than the observed amplitude (Fig. S2), which simply reflects the nature of the least-squares regression. In fact, even the raw data are unlikely to reflect the actual amplitude of the seasonal flux because of the time averaging of the sampling. Given the different time resolution and gaps, the estimate based on periodic regression is likely to be more robust. Within the limitations described above, the general performance of the periodic regression is satisfactory and allows for the objective characterisation of the seasonal shell flux patterns.

\subsection{Seasonality in shell flux}

The periodic regression analysis indicates the presence of a statistically significant cyclic component in more than $80 \%$ of the annual composite flux series (Table 2, Fig. S2). Of those cases, the majority is characterised by a single yearly flux peak. Only a single site (no. 30, off Brazil) completely lacks predictable seasonality. Other than a weak tendency for a smaller incidence of seasonality in the tropics, there is no strong pattern in the prevalence of seasonality with latitude or with annual temperature (Fig. 4a, b). The proportion of seasonal patterns characterised by two cycles per year seems to be higher at the extremes of the temperature range (Fig. 4a) and flux series with double cycles appear to be more frequently found in the Pacific Ocean (Fig. S5). The seasonal temperature range does not appear to show a relationship with the occurrence of seasonality in the shell flux, nor with the number of cycles characterising the seasonal pattern (Fig. 4c).

The peak prominence in flux series with a significant seasonal component varies between -2 and 2 , indicating differences in the peak flux over the mean flux by 4 orders of magnitude. At low latitudes seasonal shell flux patterns are characterised by generally low peak prominence, and the proportion of patterns with intermediate peak prominence $(-1$ to 0 ) decreases with latitude (Fig. 4d). Figure 4e shows that warm-water sites are indeed characterised by relatively low peak prominence, but at low temperature, peak prominence is more variable and shell flux patterns with even lower peak prominence are observed in cold waters. The seasonal temperature range seems not to be a predictor of peak prominence (Fig. 4f).

A significant seasonal component was found in the flux data for all 23 species analysed. In four species, significant cyclicity was only observed at fewer than five sites (Table 2). To avoid a bias due to low observation density, these species were excluded from analyses of species-specific patterns. Since temperature is known to be an important predictor of zooplankton phenology (Mackas et al., 2012; Richardson, 2008), we initially compared the patterns of seasonality (peak timing and peak prominence) to mean annual temperature at each site averaged over the upper $50 \mathrm{~m}$. By examining the relationship with temperature of the proportion of annual flux patterns with two cycles per year, peak timing and peak prominence, we were able to identify three groups of species with distinct modes of seasonality (Fig. 5). A particularly strong discriminator seems to be the relationship between peak prominence and temperature (see PP' in Fig. 5) and the presence of a systematic shift in peak timing with temperature. The behaviour of the species belonging to each group seems independent of the ocean basin and the presence or absence of upwelling (Figs. 5, S6).

\subsubsection{Tropical and subtropical species (group A)}

This group comprises Globigerinoides ruber (white and pink varieties), Neogloboquadrina dutertrei, G. sacculifer, Orbulina universa, G. siphonifera, Pulleniatina obliquiloculata, Globorotalia menardii, Globoturborotalita rubescens, Globoturborotalita tenella and Globigerinoides conglobatus. These species are characterised by a pattern best illustrated 


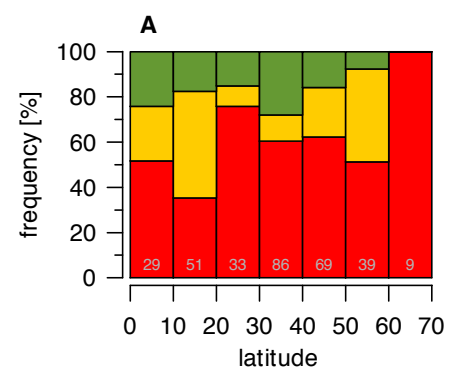

B

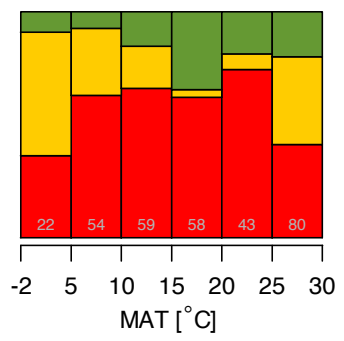

1 cycle $\mathrm{yr}^{-1} \square 2$ cycles yr $\mathrm{r}^{-1}$

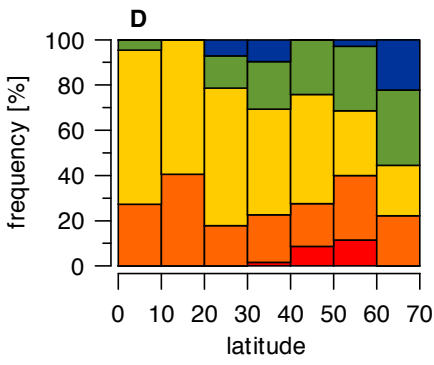

PP:
E

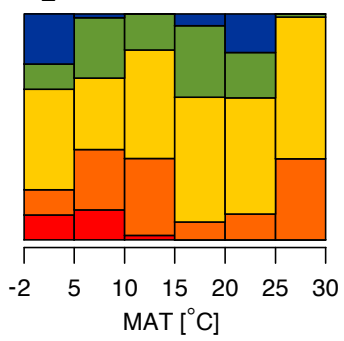

-2 to -1
C

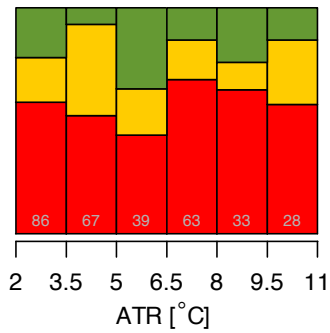

no fit

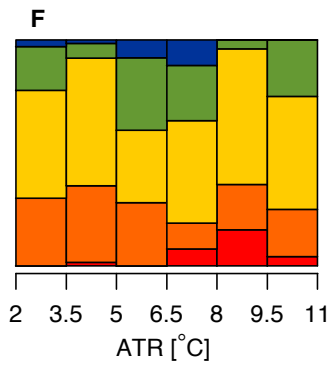

0 to $1 \square>1$

Figure 4. General patterns in shell fluxes. Top row: proportion of annual shell flux patterns showing seasonality and those characterised by one or two cycles per year vs. absolute latitude (a), mean annual temperature (b) and annual temperature range (c). Numbers denote sample size $(n)$. Bottom row: peak prominence distribution vs. same parameters as above.

by G. ruber (white) and G. sacculifer, where peak timing varies randomly in warm waters $\left(>25^{\circ} \mathrm{C}\right.$; Fig. 5a) and becomes more focussed in autumn in colder waters. Species such as $P$. obliquiloculata and $G$. menardii that have a restricted high-temperature range do not show this latter characteristic (Fig. S6). The focussing of peak timing in autumn in these species is associated with a clear increase in PP towards colder waters (Fig. 5). In the group as a whole, the temperature dependence of PP, expressed as the slope of a linear regression between PP and temperature, is negatively correlated with the mean temperature where the species is observed in our compilation $\left(T_{\text {spec }}\right)$ and positively with temperature range $\left(\Delta T_{\text {spec }}\right)\left(r^{2}=0.6\right.$ and 0.9 , respectively, excluding P. obliquiloculata; Fig. 6b, d). In addition, for a given $T_{\text {spec }}$, these species show a low proportion of flux series with two cycles per year (Table 2), and this proportion generally increases with temperature (Figs. 6a, c and S7) such that species observed in warmer waters (and observed within a narrower temperature range) have proportionally more double cycles $\left(r^{2}=0.7\right.$; Fig. $\left.6 \mathrm{c}\right)$.

\subsubsection{Temperate and cold-water species (group B)}

Globigerina bulloides, Globigerinita glutinata, T. quinqueloba, N. incompta, N. pachyderma, Globorotalia scitula, Globigerinella calida, Globigerina falconensis, Globorotalia theyeri and G. uvula form the second group. These species show a flux pattern best represented by G. glutinata
(Fig. 5), with two possible peak timings per year, both shifting towards later in the year at lower temperatures (Fig. 5b). In contrast to group $\mathrm{A}$, the proportion of records with double cycles seems to decrease with temperature in this group (Fig. S7). In some cases a third, intermediate peak time, showing a similar trend with temperature, is visible (G. $s c$ itula, G. bulloides), and in other cases (e.g. N. pachyderma) the trends are not as clear (Fig. S5). None of these species shows a clear trend in peak prominence with temperature (PP' $\sim$; Fig. 6; Table 2). With the exception of G. scitula and $G$. falconensis, the average PP of species in the group lies within a narrow range around -0.9 (Table 2) and is not related to temperature across the species in the group (Fig. 6). For any given $T_{\mathrm{spec}}$, the species show a higher proportion of series with two cycles per year than in group A (Fig. 6), but similarly to group A, the proportion of double cycles increases with $T_{\text {spec }}$ and $\Delta T_{\text {spec }}\left(r^{2}=0.7\right.$ and 0.6 respectively, excluding $G$. scitula; Fig. 6a, c).

\subsubsection{Deep dwellers (group C)}

This group consists of two species: $G$. inflata and G. truncatulinoides. Compared to the other groups, the proportion of flux series that showed only a single cycle per year is highest; only a single time series with two cycles per year is observed (Table 2). The peak timing in both species is independent of temperature and occurs everywhere in winter and early spring (Fig. 5c). Peak prominence is high (mean 0.07), 


\section{Group A}

G. ruber (white)
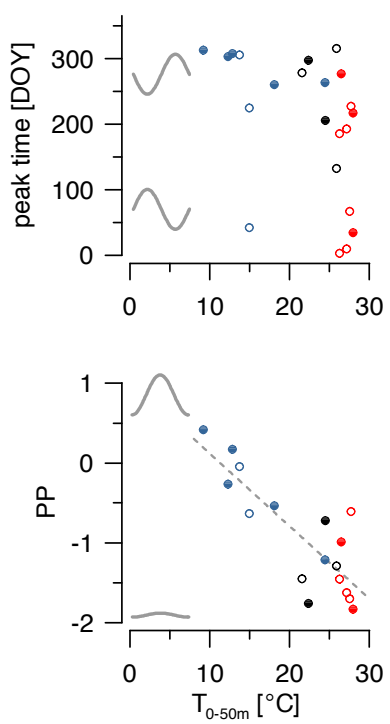

\section{Group B}

G. glutinata
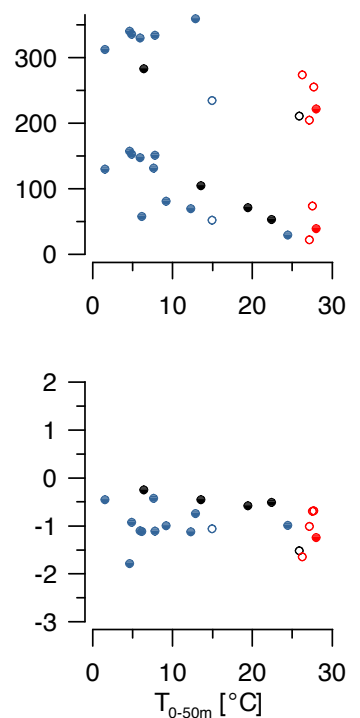

\section{Group C}

G. truncatulinoides
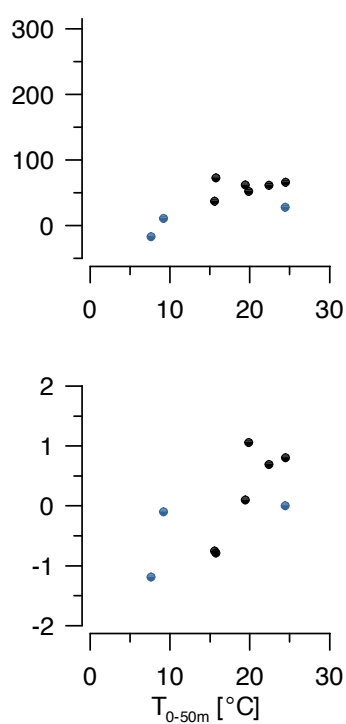

- Atlantic - Indian - Pacific open symbols denote upwelling

Figure 5. Three modes of seasonality: examples of each group; for all species see Fig. S6. Peak timing (day of year (DOY) on NH scale) and peak prominence (PP) vs. mean annual temperature between 0 and $50 \mathrm{~m}$. Group A: warm-water, symbiont-bearing species. Group B: temperate and cold-water species. Group C: deep dwellers. The grey solid curves in A illustrate the peak timing and prominence and the dashed grey line highlights the linear relation between PP and temperature (PP'). Note that peak timing represents circular data and that for G. truncatulinoides peak timing close to DOY 365 has been plotted as a negative value to highlight the pattern.

and these species are the only ones indicating a positive PP' (Figs. 5c, 6, Table 2).

\section{Discussion}

Our global compilation of shell flux time series from sediment traps shows that spatially variable seasonality is a ubiquitous and widespread phenomenon in planktonic Foraminifera. Seasonality characterises the majority of the time series investigated at any latitude or temperature (range). The amplitude of the seasonal cycle and hence the effect of seasonality on the sedimentary record varies, however, among species and with temperature. According to their seasonality pattern, the studied species can be classified into three groups. Importantly, this division holds for every ocean basin and is not affected by upwelling. This suggests that these groups reflect three principal modes of seasonality. Tropical and subtropical, mostly symbiont-bearing species (group A) adjust the peakedness of their seasonal flux pattern. Temperate and cold-water species (group B) show the opposite picture and only shift the timing of peak flux during the year without changing the peak prominence. Deep dwellers have approximately constant peak timing and change the shape of the flux pattern, but in the opposite direction from group A. Indeed, the direction of the PP change with temperature or sign of PP sensitivity (sign of PP') is the most robust discriminator between the three groups (Fig. 6).

Although the analysis revealed a high prevalence of a predictable component in the seasonal flux patterns, the periodic sinusoidal models used to detect and characterise seasonality only explained, on average, one third of the variability in the data. This may suggest that a significant part of the observed variability in the flux is not predictable. The additional variability may reflect small differences in flux timing among years, high-frequency variability such as lunar cycles, longterm trends, non-periodic events or random noise. In addition, the scatter in the data may, at least in part, also be due to the nature of the flux observations itself.

Several studies have shown that sediment traps moored at the same position but at different depths may record different shell fluxes (e.g. Curry et al., 1992; Mohiuddin et al., 2004). Such differences could be due to dissolution in the water column (Thunell et al., 1983), (lateral) advection of shells from different areas (Von Gyldenfeldt et al., 2000) or temporal lags reflecting the settling time of the shells (Takahashi and Bé, 1984). We have tried to always use the uppermost trap in order to minimise these effects, but it is im- 

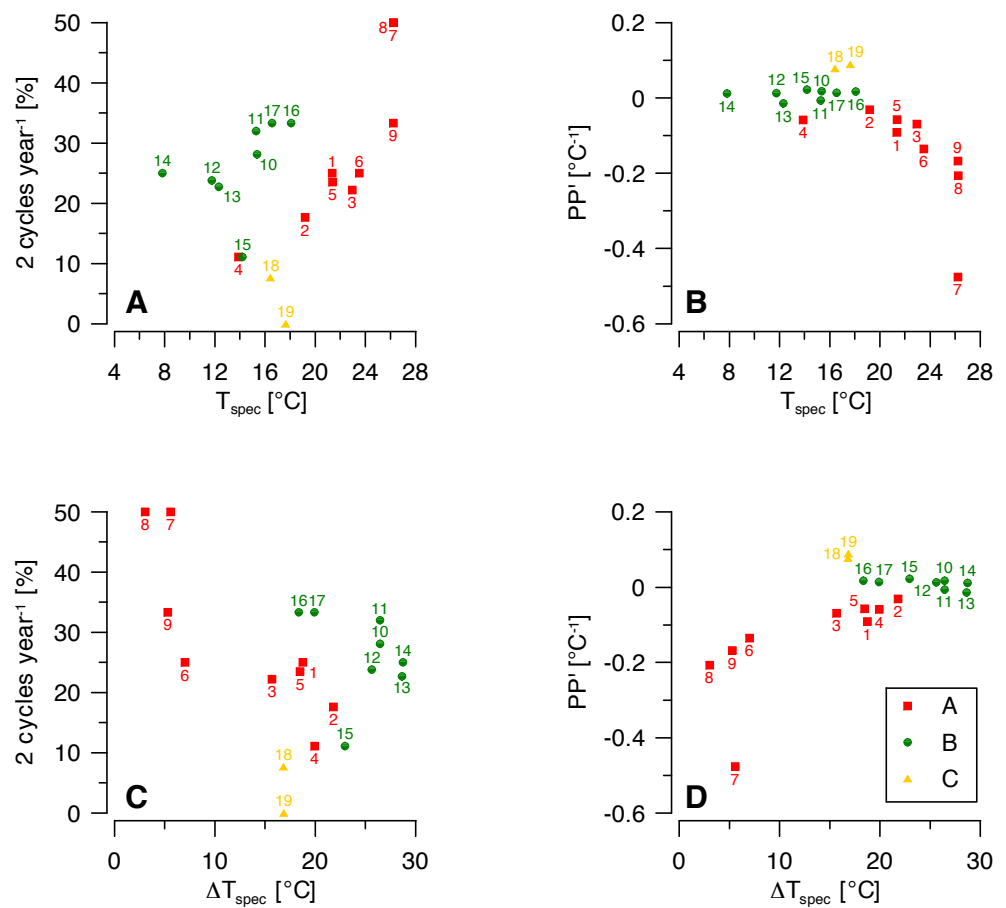

Figure 6. Scatter plots of the proportion of time series with two cycles per year (a) and temperature sensitivity of peak prominence (PP') (b) vs. temperature averaged over all sites where a species was observed $\left(T_{\text {spec }}\right)$. Panels (c) and (d) are arranged in the same way as (a) and (b), but vs. temperature range $\left(\Delta T_{\mathrm{spec}}\right)$. Individual species are numbered (see Table 2$)$.

possible to exclude the possibility that part of the observed noise in the timing and strength of species flux is due to processes that have modified the primary export flux. However, the magnitude of this error is probably within the same range as for interannual variability and therefore within the range of error of the periodic regression approach. For instance, for settling speeds, studies have shown that, depending on shell weight, size and shape, sinking speeds can vary over 2 orders of magnitude (Takahashi and Bé, 1984; Von Gyldenfeldt et al., 2000). For the deep traps, settling times could thus be as little as 4 days or as much as 1 month. This would introduce a unidirectional temporal offset from the primary signal near the ocean surface and the delivery of the flux to the sediment trap, the size of which would vary with trap depth and shell size. However, the temporal offset thus caused is within the uncertainty caused by applying the periodic regression (Fig. 2). Similarly, large seasonal changes in the catchment area and differential dissolution during settling would have most affected the deepest traps. However, because of our preference for shallower traps (only two of the analysed records are from traps moored deeper than $4000 \mathrm{~m}$ and only 11 of the 37 traps were moored deeper than $3000 \mathrm{~m}$; Table 1), this effect is probably small.

Moreover, small but consistent differences in the seasonality of shell flux in different size classes have been reported (Jonkers et al., 2013; Thunell and Reynolds, 1984). The data presented here are mostly from the more than 125 or $150 \mu \mathrm{m}$ fraction, and the fraction analysed was always held constant within each trap series. As a result, the effect of size differences on the observed phenology is probably limited. In contrast, the magnitude of the shell flux is more size dependent. Since small shells tend to be more abundant (Berger, 1969), the inclusion of smaller-sized shells could cause large changes in the amplitude of flux variation. However, including smaller specimens would also increase the background flux, and by normalising the amplitude to the mean flux (peak prominence), we have largely excluded the size effect when comparing data from different records.

Next, this compilation includes assemblage counts carried out by many different researchers. Consequently, complete taxonomic consistency between all the different studies cannot be guaranteed. This may in particular hold for the neogloboquadrinids in the Pacific, where different coiling directions are distinguished in both $N$. incompta and $N$. pachyderma (Kuroyanagi et al., 2002). Furthermore, analytical errors resulting from counting and splitting have, to our knowledge, never been properly quantified but are probably minimal compared to the size of the seasonal signal and are almost certainly random.

Even if one assumed that the flux time series are a robust representation of the flux pattern of each species as it occurred in the year of collection, the interpretation of the observed patterns could be obscured by the existence of genetic diversity within species. The analysed shell flux data are 
based on morphospecies, and many of those include multiple distinct genetic lineages ("cryptic species"), which might have distinct ecological habitats and may be endemic to separate ocean basins or regions (e.g. Darling et al., 2007). If the phenology of the constituent cryptic species were different, the patterns based on morphological species may be spurious. However, the observed modes of seasonality appear to be independent of ocean basins (Figs. 5, S6) and display consistent features among different species. This suggests that the seasonality of cryptic species is similar within one morphospecies. Apparently, ecophysiological differences between morphospecies could be responsible for some noise in the data, but they are too small to change the attribution to one of the three groups. This is consistent with the three main modes of seasonality occurring across different taxa, reflecting a functional aspect of species ecology and their environment rather than their taxonomic attribution.

\subsection{Environmental controls on shell flux seasonality}

Temperature exerts a major influence on the spatial distribution of planktonic Foraminifera species (Bé and Tolderlund, 1971; Morey et al., 2005), and it is likely that the temporal distribution (seasonality) is likewise influenced by temperature. Indeed, in other groups of zooplankton, temperature appears to be the best predictor of phenology (e.g. Mackas et al., 2012; Richardson, 2008), although the exact mechanism by which temperature controls phenology is not fully understood (Mackas et al., 2012). The three different modes of seasonality that we identified in planktonic Foraminifera also indicate that different species respond differently to changing environmental parameters, and a potential temperature effect is complex.

Temperature can affect zooplankton phenology in different ways (Mackas et al., 2012). It could directly affect phenology through the acceleration of metabolic processes. Such a direct physiological effect may be what drives, or contributes to, the earlier-when-warmer pattern in the species of group B. However, in some groups of zooplankton, the observed changes in seasonality are larger than expected from the metabolic effect of temperature alone, rendering such a direct temperature control unlikely (Mackas et al., 2012). Moreover, shell growth and survival appear to reach a saturation level at given temperatures in planktonic Foraminifera (Bijma et al., 1990); above this level temperature does not have any direct effect on flux. Consequently, a direct temperature effect is unlikely to fully explain the observed seasonal behaviour amongst the different species.

An alternative explanation for the effect of temperature on seasonality is that individual species have a thermal niche: a preferred temperature range with an optimal balance between growth and respiration. Reproductive success would then simply follow temperature, leading to the observed seasonality in the shell fluxes (e.g. Lombard et al., 2011; Zaric et al., 2005). This explanation also takes into account the dif- ferences in the temperature zonation among species (Bé and Tolderlund, 1971) and is confirmed by observations of a relationship between highest abundance and largest sizes (Hecht, 1976). It is therefore probably a better mechanism to explain the role of temperature than a direct metabolic control would be.

Finally, temperature may simply serve as a predictor or cue of optimal conditions (Mackas et al., 2012). This would imply that species use (changes in) temperature as an indication of favourable conditions to time their reproduction rather than there being any (in)direct advantages associated with a certain temperature range. Such a "signalling" role of temperature is important for reproduction timing in organisms that live in seasonally variable environments and that are dependent on correctly anticipating the arrival of optimum conditions for their offspring.

It is important to note, however, that, in large parts of the ocean, temperature is correlated to a number of other parameters, including factors that control phytoplankton productivity. Consequently, it remains difficult, in part due to the lack of data on these correlates, to assess whether temperature really is the most important factor in determining the seasonality in planktonic Foraminifera (or in zooplankton in general) or whether the correlation between temperature and seasonality is a statistical artefact.

\subsubsection{Warm-water species}

With the exception of $G$. siphonifera and $O$. universa, species in this group have relatively narrow and warm thermal optima above $20^{\circ} \mathrm{C}$ (Bé and Tolderlund, 1971; Zaric et al., 2005). At high temperatures the flux is relatively even throughout the year (low PP), and peak timing appears to be distributed throughout the year (Figs. 5, S6). Nevertheless, even at the warmest sites, the periodic regression indicates a significant seasonal component, often with two cycles per year, in the flux series of these species. Despite the low amplitude of the observed flux seasonality, the periodic model often explains a large portion of the variance in the data (e.g. $40 \%$ for G. ruber (white) at site 31 in the Mozambique Channel or over $50 \%$ for several species at site 27 in the South China Sea). However, we note that almost all of the tropical sites are affected by local seasonal change in environmental conditions, in each case reflecting different processes, such as the monsoon in the South China Sea and the Arabian Sea and upwelling in Cariaco Basin and off Java. It seems that these processes are sufficiently strong to pace the flux of planktonic Foraminifera species at most locations in the tropics, but the resulting seasonal pattern has a relatively low amplitude.

With decreasing temperature, the flux pattern of these warm-water species becomes more predictable: the peak prominence increases and peak timing is progressively focussed towards the autumn (Figs. 5, S6). This behaviour can be explained by the existence of a species-specific ther- 
mal optimum. In tropical areas, optimum temperatures occur year-round, whereas outside the tropics, they occur only for a short duration during the warm season. Consequently, these species concentrate a larger proportion of the annual flux in a shorter period (increasing PP at lower mean annual temperatures). Species showing a more restricted tropical preference show a higher PP', indicating that the tendency to concentrate the flux is greater in species with a narrow hightemperature habitat (Fig. 6). Interestingly, with decreasing temperature, only $N$. dutertre $i$ shifts its maximum flux to the period of maximum temperature, whereas the other species seem to time the flux peak to 1-2 months after the temperature peak (Figs. 7, S8). This may reflect different growth rates among these species, with $N$. dutertrei having a higher fecundity or a shorter generation time. The cessation of the peak flux would then represent a thermal barrier to reproduction or growth. In this way, the observed pattern would represent strong evidence for the existence of a thermal niche in these species.

The presence of symbionts in this group is in line with the dominant temperature control on the seasonal flux pattern of these species. With the exception of $G$. rubescens, which was never under systematic investigation, all other species in this group have been found in association with algal endosymbionts (Gastrich, 1987; Spindler and Hemleben, 1980), which decrease their reliance on primary productivity. To test this, we compared the timing of maxima in surface chlorophyll concentrations with maxima in the shell flux (Fig. 8). This analysis reveals a wide and relatively even distribution of temporal offsets between peak flux and peak productivity, indicating no relationship between these variables. Although the number of cases is relatively small, it is possible to evaluate the association between shell flux and productivity quantitatively. To this end, we consider a peak in the flux as coinciding with a chlorophyll maximum as long as the peak flux occurs within 49 days before to 79 days after the chlorophyll maximum. This interval is chosen to account for the uncertainty due to discrete observations of shell flux (average resolution of 19 days) and the chlorophyll data (resolution of 1 month), adding a plausible lag of 1 month between productivity and the response of Foraminifera. This analysis reveals a possible, statistically significant association between shell flux and productivity (confidence interval: $95 \%$; binomial test) only for $G$. siphonifera and $P$. obliquiloculata, where it is driven by observations from upwelling sites, showing a lead of Foraminifera flux peaks over productivity maxima that is within the uncertainty interval.

\subsubsection{Temperate and cold-water species}

Most species that are typically associated with temperate to cold-water conditions show two possible flux peak timings per year and exhibit a tendency to shift their peak(s) to earlier in the year at higher temperatures (Fig. 5b). Such an earlier-when-warmer trend is widely observed in other (zoo)plankton groups (Mackas et al., 2012). In this group, temperature appears to affect the timing of both flux peaks, and the earlier-when-warmer pattern suggests a temperature control on the peak timing in this group. However, a direct metabolic control on peak timing is unlikely because both seasonal flux peaks in these species do not coincide with temperature maxima. Alternatively, if the species would have a clearly defined thermal niche, it would be expected that peak fluxes occur everywhere approximately within this temperature range (but at different times in the year). However, peak fluxes in the temperate to cold-water species occur over a wide temperature range $\left(>20^{\circ} \mathrm{C}\right.$ for some species, e.g. $G$. bulloides and $G$. glutinata; see Figs. 7, S8). This indicates that the existence of species-specific thermal niches is unlikely to explain the earlier-when-warmer patterns. In fact, this is in agreement with the wide temperature tolerance for most of these species (Tolderlund and Bé, 1971; Zaric et al., 2005). Consequently, we entertain the possibility that the relationship between temperature and peak timing could stem from a correlation between temperature and the actual determinant of shell flux.

The presence of two cycles (blooms) per year, one in spring and a second after the breakdown of the summer stratification, is also a common feature of phytoplankton blooms at midlatitudes (e.g. Edwards and Richardson, 2004). The timing of these blooms is to some degree dependent on temperature, and an association of peak flux in the species of this group with productivity is thus a plausible candidate mechanism. A reliance on productivity in this group is also consistent with the lack of symbionts in most of its species. The presence of symbionts has been suggested for G. falconensis, G. glutinata and T. quinqueloba. However, Gastrich (1987) did not observe algal symbionts in G. falconensis, and the suggestion of symbionts in this species, mentioned in Spero and Parker (1985), derives from a misidentification of this species (Spero, personal communication, 2014). In addition, the presence of symbionts in T. quinqueloba is mentioned in the description of this species in Hemleben et al. (1989), but no information is provided on the origin of this observation. Only in $G$. glutinata is an association with symbionts supported by direct observations (Gastrich, 1987).

Having identified productivity as a potential factor controlling the flux phenology in temperate to cold-water planktonic Foraminifera species, we compared the timing of maxima in surface chlorophyll concentration with maxima in the shell flux, following the same approach as for the warm-water species (Fig. 8). Indeed, most species in this group show an association between the timing of peak flux and chlorophyll maxima. Only in G. calida and G. scitula is the association not statistically significant, and $G$. falconensis has too small a number of observations. The dominance of a significant relationship between the timing of shell flux and chlorophyll maxima supports previous studies that indicated a link between productivity and shell flux in the temperate species (Hemleben et al., 1989; Schiebel et al., 1997). Thus, our anal- 


\section{Group A}

G. ruber (white)

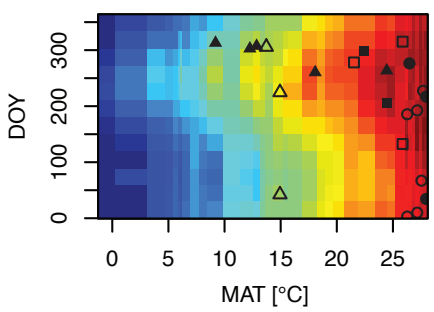

Group B

G. glutinata

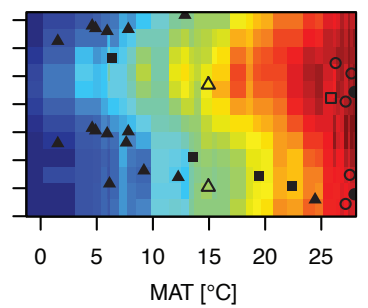

Group C

G. truncatulinoides

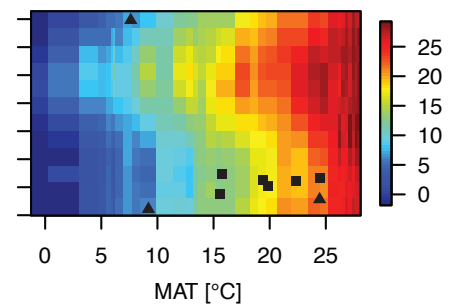

Figure 7. As Fig. 5, but peak timing patterns plotted over contour plots of annual temperature cycle. See Fig. S8 for other species. Symbols denote ocean basins: squares represent the Atlantic Ocean, circles the Indian Ocean and triangles the Pacific Ocean. Open symbols indicate sites affected by upwelling.

ysis suggests that the timing of primary productivity serves as a predictor of peak flux timing in the temperate to coldwater species.

\subsubsection{Deep-dwelling species}

Of the three deep-dwelling species analysed, two appear to show a unique pattern of seasonality, distinct from both groups described above. Whereas $G$. scitula shows a pattern consistent with group B, the peak flux of $G$. truncatulinoides and $G$. inflata is observed around the same time in winter or spring (Fig. 5c) and a large proportion of the annual flux occurs in a single high-flux pulse (high PP, low percentage of double cycles; Table 2). Both characteristics might relate to a longer life cycle, as proposed for G. truncatulinoides (Hemleben et al., 1989). The two species show a (weak) positive correlation between peak prominence and temperature (Fig. 5c), which could indicate higher year-round reproductive success at lower temperatures, in agreement with the preferred peak timing around the coldest time of the year and also with their preferred temperature range (Bé and Tolderlund, 1971; Tolderlund and Bé, 1971). Alternatively, the more evenly distributed seasonal flux pattern outside the tropics could reflect a higher proportion of expatriated specimens that have higher mortality outside the peak flux period, but this does not agree with the higher abundance of both species at lower temperatures (Bé and Tolderlund, 1971; Tolderlund and Bé, 1971). As expected, because of the relatively constant timing of peak flux in both species, there is no association between the timing of their flux and that of productivity.

The peak shell flux around the coldest month during the year (clearest in G. truncatulinoides) argues against a direct metabolic influence of temperature on the peak timing. Similarly, if these species had a well-defined thermal niche between $\sim 10$ and $24^{\circ} \mathrm{C}$, as suggested by Bé and Tolderlund (1971), one would expect that, at both ends of that temperature range, the peak flux would represent a larger proportion of the total annual flux because the seasonal growth window would have become shorter. However, we do not observe such an increase in the PP at the cold end of the temperature range (Fig. 5c). This argues against temperature controlling the seasonal pattern and suggests that either some correlated factors determine the seasonality in this group or that the species use some feature of the seasonal temperature cycle as a cue to anticipate optimal conditions for their offspring. Although both species are considered deep dwellers, they migrate vertically through the water column and spend a significant part of their life cycle relatively close to the sea surface (Field, 2004; Loncaric et al., 2006; Tolderlund and Bé, 1971). Thus, the trigger for the regular flux pulse could originate from conditions close to the surface, where seasonal environmental changes tend to be of a higher magnitude.

\subsection{Paleoceanographic implications}

The existence of a significant seasonal component in the shell flux pattern of extant planktonic Foraminifera has implications for the interpretation of the fossil record. Since seasonality is species-specific and spatially variable, fossil assemblages of the same species collected at different locations contain a different amount of seasonal bias in the composition of their shells. Firstly, this may affect proxy calibrations based on sediment core tops, which, depending on their location, will reflect a variable amount of seasonal bias and not reflect mean annual conditions. Because of such seasonal bias, determining the environmental niche of a certain species using mean annual conditions leads to an overestimation of the width of this niche. Consequently, under these assumptions, calibration based on mean annual environmental conditions may not be meaningful. Hönisch et al. (2013) provide an instructive example of how seasonality may affect $\mathrm{Mg} / \mathrm{Ca}$ temperature calibration, but seasonal biasing may also affect multivariate biotic approaches based on foraminiferal assemblages.

Secondly, this spatial bias may translate into a temporal bias in records straddling climatic transitions. The size of the 
Group A G. ruber (white)

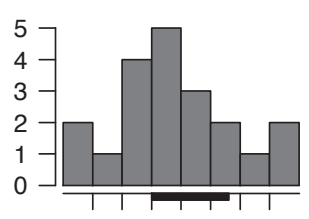

O. universa

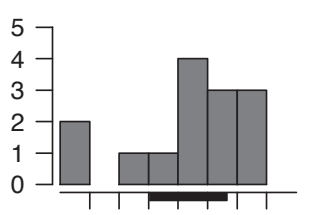

P. obliquiloculata*

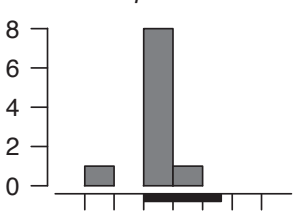

G. ruber (pink)

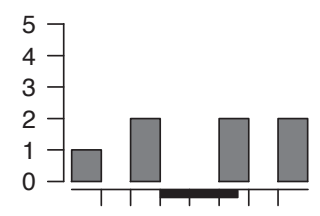

N. dutertrei

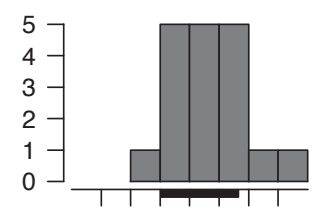

G. sacculifer

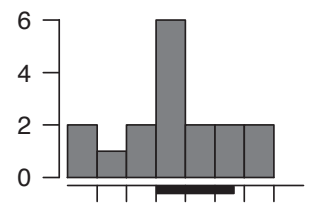

G. menardii

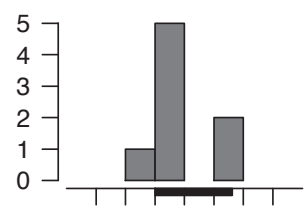

G. rubescens

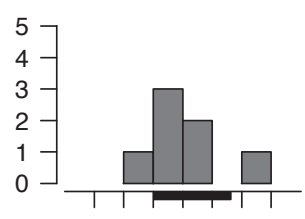

G. siphonifera*

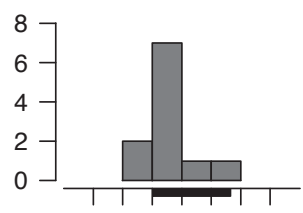

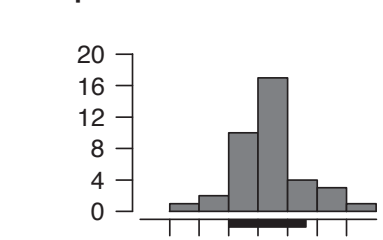

G. glutinata*

T. quinqueloba*

N. incompta*

N. pachyderma*
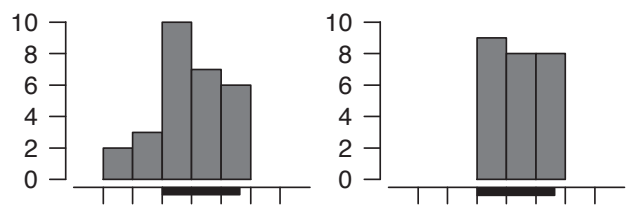

G. scitula
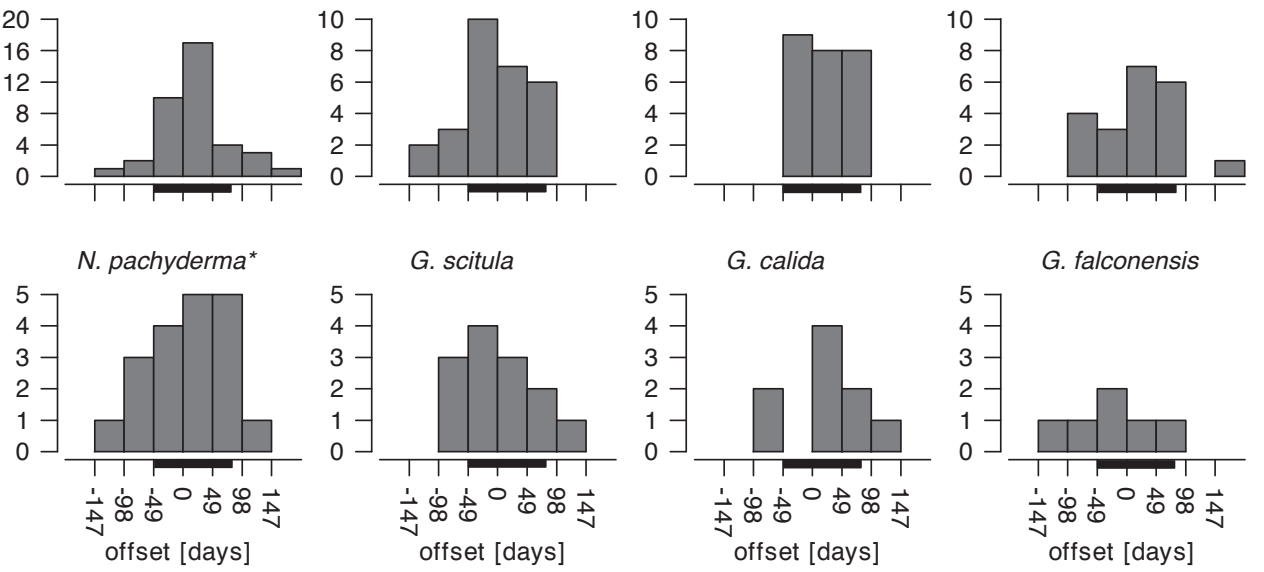

G. calida

G. falconensis
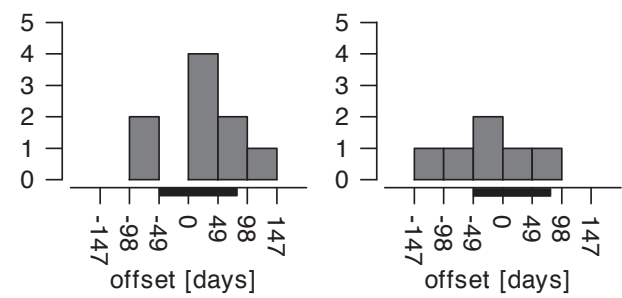

Figure 8. Productivity and peak timing in groups A and B. Histograms of the residual of chlorophyll maxima and peak flux timing. Zero and positive offsets suggest an association between shell flux peaks and productivity. The interval used for the binomial test is highlighted by the black horizontal bar, and species that show a statistically significant association $(p \leq 0.05)$ between shell flux peak timing and productivity are marked with an asterisk.

bias is a function of the amplitude of the seasonal cycle (PP), the variance in the timing of peak flux and the interannual amplitude of the change in the environmental parameter to be reconstructed. Our compilation of shell flux time series allows an assessment of the potential size of such a bias in the fossil record by calculating a flux-weighted average temperature for a synthetic sample that would be deposited below the location of each trap. Figure 9 shows the spatial distribution of the seasonal bias within each species expressed as a difference between the flux-weighted temperature and the mean annual temperature (0-50 m water depth). Speciesspecific depth habitats were not taken into account in the cal- culation of these offsets, which likely leads to an overestimation of the size of the bias for deep-dwelling species. If the flux of a species is even throughout the year or the temperature does not vary, the offset would tend to zero. If the flux shows peaks of similar size and constant timing, the offsets for one species will always have the same sign. In all other cases the distribution of the bias will be more complex, precluding generalisations, such as a classification into summer or winter species.

The temperature offsets due to seasonality vary between +4 and $-4^{\circ} \mathrm{C}$ and may range by as much as $6^{\circ} \mathrm{C}$ within one species (Fig. 9). At a single location, species with a dif- 

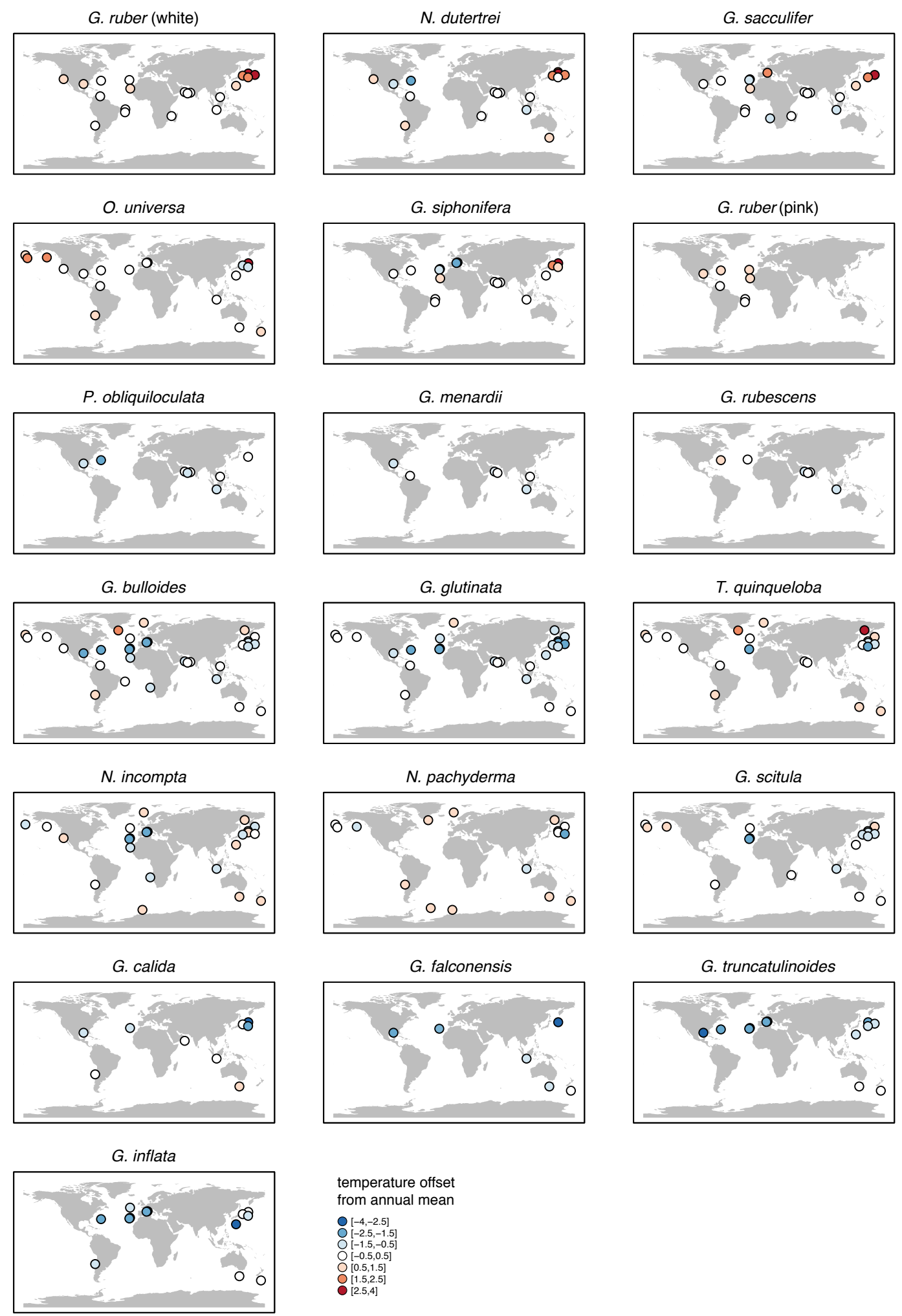

Figure 9. Offset from mean temperature $(0-50 \mathrm{~m}$ water depth) due to seasonality. Positive offsets indicate that flux-weighted temperature is higher than mean temperature and vice versa. 
ferent seasonality mode may show different flux-weighted offsets. This is more likely to occur at intermediate temperatures where warm and cold-water species mix and has been observed previously (Jonkers et al., 2013; King and Howard, 2005). Large positive offsets are generally found at higher latitudes, reflecting a preference for summer flux in colder regions. As a result of the earlier-when-warmer trend in peak timing, negative offsets are observed in temperate zones in many species of group B. The offsets are often larger than the uncertainty of $\mathrm{Mg} / \mathrm{Ca}$ temperature estimates (about $1^{\circ} \mathrm{C}$; Anand et al., 2003) and translate to an approximately $2 \%$ range in $\delta^{18} \mathrm{O}$. This means the present-day spatial pattern in temperature offsets due to varying flux seasonality within a species could be large enough to explain the magnitude of glacial-interglacial change in most parts of the ocean (MARGO project, 2009). Indeed, seasonality has been invoked as a possible explanation of the observed discrepancy between $\mathrm{Mg} / \mathrm{Ca}$ paleotemperatures, other paleothermometers and climate models (Laepple and Huybers, 2013; Leduc et al., 2010; Lohmann et al., 2013).

In addition, changes in the shape of the seasonal flux pattern, particularly in the peak prominence, could influence the variability in proxy records. A seasonal flux pattern with higher PP means that the Foraminifera register ambient seawater conditions during a shorter interval in the year and this will result in a narrower distribution of individual shell signatures in the sediment. This not only reduces intra-sample variability but, since only a small fraction of the total number of Foraminifera is used for analysis, also the variability between samples (Laepple and Huybers, 2013).

Both effects clearly illustrate the importance of seasonal variation in shell fluxes on the fossil record and the need to take potential transient changes in seasonality into account. Importantly, a transient change in the seasonal bias as a result of changing environmental factors will depend on the mode of seasonality that characterises the species. Thus, although the magnitude of the temperature offsets due to seasonality is large within species (Fig. 9), in reality, the presence of the distinct seasonality modes means that the expected bias through time due to shifting seasonality varies predictably in its sign and magnitude.

Within the optimal temperature range of warm-water species (group A), seasonal variation in the shell flux is low, and these species thus record average annual conditions with very little offset (Fig. 9). However, outside their optimum temperature range, these species concentrate a progressively larger portion of their annual flux into a single peak in autumn, leading to an increasingly positive bias from mean annual conditions. Consequently, during a cooling trend, the seasonality of these species would shift towards the summer and the proxies based on such species would underestimate the magnitude of the temperature shift. Conversely, during a warming trend, these species will shift their seasonality from dominantly autumn to a more even flux throughout the year, also leading to an underestimation of the actual change in mean temperature. The resulting intra-sample variability due to seasonality will remain similar, so single-shell analyses are unlikely to resolve this effect. Because of the observed pattern of shifting peak timing at present, temperate and cold-water species (group B) are most likely to exhibit transient changes in seasonality. As is the case in group A, a shift in seasonality during climate transitions will lead to an underestimation of the actual environmental changes reconstructed using these species. During a warming trend, these species will shift the peak timing towards earlier in the year, recording lower temperatures and vice versa. Finally, the fossil record of deep-dwelling species (group C) predominantly reflects late winter or spring conditions. However, as the peak prominence in this group increases with temperature, this seasonal bias is larger at higher temperatures. Thus, during a warming trend, more of the flux is focussed in the narrow seasonal peak and the species records lower temperature, underestimating the amplitude of temperature change. During a cooling trend, the flux is less focussed, recording on average warmer conditions. Thus, remarkably, despite the three principle modes of seasonality, transient changes in seasonality always result in an underestimation of the amplitude of environmental change recorded in fossil Foraminifera.

The recognition of the existence of distinct modes of seasonality in planktonic Foraminifera provides an important perspective for the validation of planktonic Foraminifera growth models (Fraile et al., 2009a; Lombard et al., 2011; Zaric et al., 2006). Rather than validating models by evaluating their performance at individual sites, it should be possible to diagnose whether the model representation of individual species is consistent with their observed seasonality mode. Alternatively, the observed seasonality patterns can be used to guide model development. For example, the strong relationship between PP and mean annual temperature in group A, combined with the tendency to shift peak time towards autumn, should be relatively easy to parametrise and implement, potentially allowing a more powerful prediction of the effect of seasonality on the fossil record of species in this group. Similarly, in group B, peak timing shows a strong association with productivity. Primary productivity is explicitly simulated in some models (e.g. Henson et al., 2009), offering the chance to predict changes in seasonality of species in this group from the seasonality of primary production. A combination of models with a realistic representation of species seasonality with proxy data certainly holds the best potential to estimate the actual amplitude of past environmental change recorded in shells of planktonic Foraminifera.

\section{Conclusions}

Our systematic overview revealed that all 23 species of planktonic Foraminifera studied have a predictable cyclic component in the intra-annual variability in their shell fluxes. This seasonality is spatially variable within individ- 
ual species and, depending on the species, predominantly driven by temperature or by primary productivity. We identified three groups of species with similar modes of seasonality:

1. Tropical and subtropical species (G. ruber (white and pink varieties), $N$. dutertrei, G. sacculifer, O. universa, G. siphonifera, P. obliquiloculata, G. menardii, G. rubescens, G. tenella and G. conglobatus) have relatively even flux patterns, with low prominence peaks occurring at any time of the year in their optimum high-temperature range $\left(>25^{\circ} \mathrm{C}\right)$. In colder waters peak fluxes become more prominent and focussed in autumn. This tendency is stronger in species with a narrow thermal range. The prevalence of endosymbionts in these species probably reduces their reliance on primary production for food. Indeed, seasonality in this group appears to be primarily driven by temperature, suggesting the existence of a thermal niche for these species.

2. Temperate and cold-water species (Globigerina bulloides, G. glutinata, T. quinqueloba, N. incompta, $N$. pachyderma, G. scitula, G. calida, G. falconensis, G. theyeri and G. uvula) show one or two cycles per year and peak flux timing occurs later in the year at lower temperatures. Peak timing in this group occurs at the same time or slightly after maximum chlorophyll concentration, suggesting a tight link between primary productivity and shell flux seasonality in these dominantly symbiont-barren species.

3. Deep-dwelling species (G. inflata and G. truncatulinoides) always reach peak flux in winter or spring independently of temperature and productivity, but they concentrate a larger proportion of the annual flux into short periods in warmer waters.

The environmental control on shell flux seasonality implies that changes in seasonality are likely to have occurred during past climate change, leading to a change in the seasonal bias in foraminiferal proxy records through time. Our analysis indicates that the effect of this changing seasonal bias leads to an underestimation of the change in mean conditions, irrespective of the seasonality mode. Moreover, the recognition of the three principal modes in seasonality offers opportunities to test and improve foraminiferal growth models, ultimately allowing for improved reconstructions of climate change.

\section{The Supplement related to this article is available online at doi:10.5194/bg-12-2207-2015-supplement.}

Acknowledgements. We thank all researchers who shared their sediment trap time series data and William Howard and an anonymous reviewer for their positive reviews of a previous version of this paper. This work was carried out within the framework of the SCOR/IGBP working group 138: Modern Planktonic Foraminifera and Ocean Changes. We thank Caroline Cléroux for her help in initiating this project. L. Jonkers is funded through the Climate Change Consortium of Wales (C3Wales.org).

Edited by: H. Kitazato

\section{References}

Alderman, S. E.: Planktonic Foraminifera in the Sea of Okhotsk: Population and Stable Isotopic Analysis from a Sediment Trap, M.Sc., MIT/WHOI, Cambridge, MS, 99 pp., 1996.

Anand, P., Elderfield, H., and Conte, M. H.: Calibration of $\mathrm{Mg} / \mathrm{Ca}$ thermometry in planktonic foraminifera from a sediment trap time series, Paleoceanography, 18, 1050, doi:10.1029/2002pa000846, 2003.

Asahi, H. and Takahashi, K.: A 9-year time-series of planktonic foraminifer fluxes and environmental change in the Bering sea and the central subarctic Pacific Ocean, 1990-1999, Progr. Oceanogr., 72, 343-363, doi:10.1016/j.pocean.2006.03.021, 2007.

Batchelet, E.: Circular Statistics in Biology, Academic Press, London, 371 pp., 1981.

Bé, A. W. H.: Ecology of Recent planktonic foraminifera - Part 2, Bathymetric and seasonal distributions in the Sargasso Sea off Bermuda, Micropaleontology, 6, 373-392, 1960.

Bé, A. W. H. and Tolderlund, D. S.: Distribution and ecology of living planktonic foraminifera in surface waters of the Atlantic and Indian Oceans, The Micropaleontology of Oceans, Cambridge University Press, Cambridge, 105-149, 1971.

Bell, K. N. I., Cowley, P. D., and Whitfield, A. K.: Seasonality in Frequency of Marine Access to an Intermittently Open Estuary: Implications for Recruitment Strategies, Estuarine, Coast. Shelf Sci., 52, 327-337, doi:10.1006/ecss.2000.0709, 2001.

Berger, W. H.: Ecologic patterns of living planktonic Foraminifera, Deep-Sea Res., 16, 1-24, doi:10.1016/0011-7471(69)90047-3, 1969.

Bijma, J., Faber, W. W., and Hemleben, C.: Temperature and salinity limits for growth and survival of some planktonic foraminifers in laboratory cultures, J. Foramin. Res., 20, 95-116, 1990.

Curry, W. B., Ostermann, D. R., Guptha, M. V. S., and Ittekkot, V.: Foraminiferal production and monsoonal upwelling in the Arabian Sea: evidence from sediment traps, Geological Society, London, Special Publications, 64, 93-106, doi:10.1144/gsl.sp.1992.064.01.06, 1992.

Darling, K. F., Kucera, M., Wade, C. M., von Langen, P., and Pak, D.: Seasonal distribution of genetic types of planktonic foraminifer morphospecies in the Santa Barbara Channel and its paleoceanographic implications, Paleoceanography, 18, 1032, doi:10.1029/2001pa000723, 2003.

Darling, K. F., Kucera, M., and Wade, C. M.: Global molecular phylogeography reveals persistent Arctic circumpolar isolation in a marine planktonic protist, P. Natl. Acad. Sci., 104, 5002-5007, doi:10.1073/pnas.0700520104, 2007. 
deBruyn, A. M. H. and Meeuwig, J. J.: Detecting lunar cycles in marine ecology: periodic regression versus categorical ANOVA, Mar. Ecol.-Prog. Ser., 214, 307-310, doi:10.3354/meps214307, 2001.

Deuser, W. G. and Ross, E. H.: Seasonally abundant planktonic foraminifera of the Sargasso Sea; succession, deep-water fluxes, isotopic compositions, and paleoceanographic implications, J. Foramin. Res., 19, 268-293, 1989.

Deuser, W. G., Ross, E. H., Hemleben, C., and Spindler, M.: Seasonal changes in species composition, numbers, mass, size, and isotopic composition of planktonic foraminifera settling into the deep sargasso sea, Palaeogeogr. Palaeocl., 33, 103-127, doi:10.1016/0031-0182(81)90034-1, 1981.

Donner, B. and Wefer, G.: Flux and stable isotope composition of Neogloboquadrina pachyderma and other planktonic foraminifers in the Southern Ocean (Atlantic sector), Deep-Sea Res. Pt. I, 41, 1733-1743, doi:10.1016/0967-0637(94)90070-1, 1994.

Drolet, D. and Barbeau, M. A.: Diel and Semi-Lunar Cycles in the Swimming Activity of the Intertidal, Benthic Amphipod in the Upper Bay of Fundy, Canada, 29, 51-56, doi:10.1651/08-3010.1, 2009.

Edwards, M. and Richardson, A. J.: Impact of climate change on marine pelagic phenology and trophic mismatch, Nature, 430, 881-884, doi:10.1038/nature02808, 2004.

Fallet, U., Brummer, G.-J., Zinke, J., Vogels, S., and Ridderinkhof, H.: Contrasting seasonal fluxes of planktonic foraminifera and impacts on paleothermometry in the Mozambique Channel upstream of the Agulhas Current, Paleoceanography, 25, PA4223, doi:10.1029/2010pa001942, 2010.

Fallet, U., Ullgren, J. E., Castañeda, I. S., van Aken, H. M., Schouten, S., Ridderinkhof, H., and Brummer, G.-J. A.: Contrasting variability in foraminiferal and organic paleotemperature proxies in sedimenting particles of the Mozambique Channel (SW Indian Ocean), Geochim. Cosmochim. Ac., 75, 5834-5848, doi:10.1016/j.gca.2011.08.009, 2011.

Field, D. B.: Variability in vertical distributions of planktonic foraminifera in the California Current: Relationships to vertical ocean structure, Paleoceanography, 19, PA2014, doi:10.1029/2003pa000970, 2004.

Fischer, G., Donner, B., Ratmeyer, V., Davenport, R., and Wefer, G.: Distinct year-to-year particle flux variations off Cape Blanc during 1988-1991: Relation to delta18O-deduced seasurface temperatures and trade winds, J. Mar. Res., 54, 73-98, doi:10.1357/0022240963213484, 1996.

Fraile, I., Schulz, M., Mulitza, S., and Kucera, M.: Predicting the global distribution of planktonic foraminifera using a dynamic ecosystem model, Biogeosciences, 5, 891-911, doi:10.5194/bg5-891-2008, 2008.

Fraile, I., Mulitza, S., and Schulz, M.: Modeling planktonic foraminiferal seasonality: Implications for sea-surface temperature reconstructions, Mar. Micropaleontol., 72, 1-9, doi:10.1016/j.marmicro.2009.01.003, 2009a.

Fraile, I., Schulz, M., Mulitza, S., Merkel, U., Prange, M., and Paul, A.: Modeling the seasonal distribution of planktonic foraminifera during the Last Glacial Maximum, Paleoceanography, 24, PA2216, doi:10.1029/2008PA001686, 2009 b.
Gastrich, M. D.: Ultrastructure of a new intracellular symbiotic alga found within planktonic foraminifera, J. Phycol., 23, 623-632, doi:10.1111/j.1529-8817.1987.tb04215.x, 1987.

Gerritsen, H.: Data visualisation on maps (mapplots R package), version 1.2, 2012.

Hecht, A. D.: An ecologic model for test size variation in Recent planktonic foraminifera; applications to the fossil record, J. Foramin. Res., 6, 295-311, doi:10.2113/gsjfr.6.4.295, 1976.

Hemleben, C., Spindler, M., and Anderson, O. R.: Modern Planktonic Foraminifera, Springer Verlag, Berlin, 363 pp., 1989.

Henson, S. A., Dunne, J. P., and Sarmiento, J. L.: Decadal variability in North Atlantic phytoplankton blooms, J. Geophys. Res.Oceans, 114, C04013, doi:10.1029/2008jc005139, 2009.

Hönisch, B., Allen, K. A., Lea, D. W., Spero, H. J., Eggins, S. M., Arbuszewski, J., deMenocal, P., Rosenthal, Y., Russell, A. D., and Elderfield, $\mathrm{H}$.: The influence of salinity on $\mathrm{Mg} / \mathrm{Ca}$ in planktic foraminifers - Evidence from cultures, core-top sediments and complementary $\delta^{18} \mathrm{O}$, Geochim. Cosmochim. Ac., 121, 196213, doi:10.1016/j.gca.2013.07.028, 2013.

Jensen, S.: Planktische Foraminiferen im Europäischen Nordmeer: Verbreitung und Vertikalfluss sowie ihre Verbreitung während der letzten 15000 Jahre, Berichte Sonderforschungsbereich, 313, 75, 1-105, 1998.

Jonkers, L., Brummer, G.-J. A., Peeters, F. J. C., van Aken, H. M., and De Jong, M. F.: Seasonal stratification, shell flux, and oxygen isotope dynamics of left-coiling $N$. pachyderma and T. quinqueloba in the western subpolar North Atlantic, Paleoceanography, 25, PA2204, doi:10.1002/palo.20018, 2010.

Jonkers, L., van Heuven, S., Zahn, R., and Peeters, F. J. C.: Seasonal patterns of shell flux, $\delta^{18} \mathrm{O}$ and $\delta^{13} \mathrm{C}$ of small and large $N$. pachyderma (s) and G. bulloides in the subpolar North Atlantic, Paleoceanography, 28, 164-174, doi:10.1002/palo.20018, 2013.

Kincaid, E., Thunell, R. C., Le, J., Lange, C. B., Weinheimer, A. L., and Reid, F. M. H.: Planktonic foraminiferal fluxes in the Santa Barbara Basin: response to seasonal and interannual hydrographic changes, Deep-Sea Res. Pt. II, 47, 1157-1176, doi:10.1016/S0967-0645(99)00140-X, 2000.

King, A. L. and Howard, W. R.: Planktonic foraminiferal flux seasonality in Subantarctic sediment traps: A test for paleoclimate reconstructions, Paleoceanography, 18, 1019, doi:10.1029/2002pa000839, 2003.

King, A. L. and Howard, W. R.: $\delta^{18} \mathrm{O}$ seasonality of planktonic foraminifera from Southern Ocean sediment traps: Latitudinal gradients and implications for paleoclimate reconstructions, Mar. Micropaleontol., 56, 1-24, 2005.

Kuroyanagi, A., Kawahata, H., Nishi, H., and Honda, M. C.: Seasonal changes in planktonic foraminifera in the northwestern North Pacific Ocean: sediment trap experiments from subarctic and subtropical gyres, Deep-Sea Res. Pt. II, 49, 5627-5645, doi:10.1016/s0967-0645(02)00202-3, 2002.

Laepple, T. and Huybers, P.: Reconciling discrepancies between Uk37 and $\mathrm{Mg} / \mathrm{Ca}$ reconstructions of Holocene marine temperature variability, Earth Planet. Sci. Lett., 375, 418-429, doi:10.1016/j.epsl.2013.06.006, 2013.

Leduc, G., Schneider, R., Kim, J. H., and Lohmann, G.: Holocene and Eemian sea surface temperature trends as revealed by alkenone and $\mathrm{Mg} / \mathrm{Ca}$ paleothermometry, Quaternary Sci. Rev., 29, 989-1004, doi:10.1016/j.quascirev.2010.01.004, 2010. 
Locarnini, R. A., Mishonov, A. V., Antonov, J. I., Boyer, T. P., Garcia, H. E., Baranova, O. K., Zweng, M. M., and Johnson, D. R.: World Ocean Atlas 2009, Volume 1: Temperature, in: NOAA Atlas NESDIS 68, edited by: Levitus, S., U.S. Government Printing Office, Washington, D.C., 184 pp., 2010.

Lohmann, G., Pfeiffer, M., Laepple, T., Leduc, G., and Kim, J.-H.: A model-data comparison of the Holocene global sea surface temperature evolution, Clim. Past, 9, 1807-1839, doi:10.5194/cp-9-1807-2013, 2013.

Lombard, F., Labeyrie, L., Michel, E., Bopp, L., Cortijo, E., Retailleau, S., Howa, H., and Jorissen, F.: Modelling planktic foraminifer growth and distribution using an ecophysiological multi-species approach, Biogeosciences, 8, 853-873, doi:10.5194/bg-8-853-2011, 2011

Loncaric, N., Peeters, F. J. C., Kroon, D., and Brummer, G. J. A.: Oxygen isotope ecology of recent planktic foraminifera at the central Walvis Ridge (SE Atlantic), Paleoceanography, 21, PA3009, doi:10.1029/2005PA001207, 2006.

Mackas, D. L., Greve, W., Edwards, M., Chiba, S., Tadokoro, K., Eloire, D., Mazzocchi, M. G., Batten, S., Richardson, A. J., Johnson, C., Head, E., Conversi, A., and Peluso, T.: Changing zooplankton seasonality in a changing ocean: Comparing time series of zooplankton phenology, Progr. Oceanogr., 97-100, 31-62, doi:10.1016/j.pocean.2011.11.005, 2012.

Marchant, M., Hebbeln, D., and Wefer, G.: Seasonal flux patterns of planktic foraminifera in the Peru-Chile current, Deep-Sea Res. Pt. I, 45, 1161-1185, doi:10.1016/S0967-0637(98)00009-0, 1998.

Marchant, M., Hebbeln, D., Giglio, S., Coloma, C., and González, H. E.: Seasonal and interannual variability in the flux of planktic foraminifera in the Humboldt Current System off central Chile $\left(30^{\circ} \mathrm{S}\right)$, Deep-Sea Res. Pt. II, 51, 2441-2455, doi:10.1016/j.dsr2.2004.08.013, 2004.

MARGO project: Constraints on the magnitude and patterns of ocean cooling at the Last Glacial Maximum, Nat. Geosci., 2, 127-132, 2009.

Mohiuddin, M. M., Nishimura, A., Tanaka, Y., and Shimamoto, A.: Regional and interannual productivity of biogenic components and planktonic foraminiferal fluxes in the northwestern Pacific Basin, Mar. Micropaleontol., 45, 57-82, doi:10.1016/S03778398(01)00045-7, 2002.

Mohiuddin, M. M., Nishimura, A., Tanaka, Y., and Shimamoto, A.: Seasonality of biogenic particle and planktonic foraminifera fluxes: response to hydrographic variability in the Kuroshio Extension, northwestern Pacific Ocean, Deep-Sea Res. Pt. I, 51, 1659-1683, doi:10.1016/j.dsr.2004.06.002, 2004.

Mohiuddin, M. M., Nishimura, A., and Tanaka, Y.: Seasonal succession, vertical distribution, and dissolution of planktonic foraminifera along the Subarctic Front: Implications for paleoceanographic reconstruction in the northwestern Pacific, Mar. Micropaleontol., 55, 129-156, 2005.

Mohtadi, M., Steinke, S., Groeneveld, J., Fink, H. G., Rixen, T., Hebbeln, D., Donner, B., and Herunadi, B.: Low-latitude control on seasonal and interannual changes in planktonic foraminiferal flux and shell geochemistry off south Java: A sediment trap study, Paleoceanography, 24, PA1201, doi:10.1029/2008PA001636, 2009.

Morey, A. E., Mix, A. C., and Pisias, N. G.: Planktonic foraminiferal assemblages preserved in surface sediments correspond to mul- tiple environment variables, Quaternary Sci. Rev., 24, 925-950, doi:10.1016/j.quascirev.2003.09.011, 2005.

Northcote, L. C. and Neil, H. L.: Seasonal variations in foraminiferal flux in the Southern Ocean, Campbell Plateau, New Zealand, Mar. Micropaleontol., 56, 122-137, doi:10.1016/j.marmicro.2005.05.001, 2005.

Ortiz, J. D. and Mix, A. C.: The spatial distribution and seasonal succession of planktonic foraminifera in the California Current off Oregon, September 1987-September 1988, Geological Society, London, Special Publications, 64, 197-213, doi:10.1144/gsl.sp.1992.064.01.13, 1992.

Ortiz, J. D., Mix, A. C., and Collier, R. W.: Environmental Control of Living Symbiotic and Asymbiotic Foraminifera of the California Current, Paleoceanography, 10, 987-1009, 1995.

Poore, R. Z., Tedesco, K. A., and Spear, J. W.: Seasonal Flux and Assemblage Composition of Planktic Foraminifers from a Sediment-Trap Study in the Northern Gulf of Mexico, J. Coast. Res., 63, 6-19, doi:10.2112/si63-002.1, 2013.

$\mathrm{R}$ core team: $\mathrm{R}$ : A language and environment for statistical computing, 2013.

Reynolds, C. E., Richey, J. N., and Poore, R. Z.: Seasonal flux and assemblage composition of planktic foraminifera from the northern Gulf of Mexico, 2008-2012, Reston, Virginia, 13, 13 pp., 2013.

Richardson, A. J.: In hot water: zooplankton and climate change, ICES J. Mar. Sci., 65, 279-295, doi:10.1093/icesjms/fsn028, 2008.

Rigual-Hernández, A. S., Sierro, F. J., Bárcena, M. A., Flores, J. A., and Heussner, S.: Seasonal and interannual changes of planktic foraminiferal fluxes in the Gulf of Lions (NW Mediterranean) and their implications for paleoceanographic studies: Two 12year sediment trap records, Deep-Sea Res. Pt. I, 66, 26-40, doi:10.1016/j.dsr.2012.03.011, 2012.

Saher, M. H., Peeters, F. J. C., and Kroon, D.: Sea surface temperatures during the SW and NE monsoon seasons in the western Arabian Sea over the past 20000 years, Palaeogeogr. Palaeocl., 249, 216-228, doi:10.1016/j.palaeo.2007.01.014, 2007.

Sautter, L. R. and Thunell, R. C.: Seasonal succession of planktonic foraminifera, results from a four-year time-series sediment trap experiment in the Northeast Pacific, J. Foramin. Res., 19, 253267, doi:10.2113/gsjfr.19.4.253, 1989.

Schiebel, R.: Planktic foraminiferal sedimentation and the marine calcite budget, Global Biogeochem. Cy., 16, 1065, doi:10.1029/2001gb001459, 2002.

Schiebel, R., Bijma, J., and Hemleben, C.: Population dynamics of the planktic foraminifer Globigerina bulloides from the eastern North Atlantic, Deep-Sea Res. Pt. I, 44, 1701-1713, doi:10.1016/s0967-0637(97)00036-8, 1997.

Schneider, B., Leduc, G., and Park, W.: Disentangling seasonal signals in Holocene climate trends by satellitemodel-proxy integration, Paleoceanography, 25, PA4217, doi:10.1029/2009pa001893, 2010.

Spero, H. J. and Parker, S. L.: Photosynthesis in the symbiotic planktonic foraminifer Orbulina universa, and its potential contribution to oceanic primary productivity, J. Foramin. Res., 15, 273-281, doi:10.2113/gsjfr.15.4.273, 1985.

Spindler, M. and Hemleben, C.: Symbionts in planktonic foraminifera (Protozoa), Endocytobiology, Endosymbiosis and 
Cell Biology, New York: Walter de Gruyter \& Co, 133-140, 1980.

Spindler, M., Hemleben, C., Bayer, U., Bé, A., and Anderson, O.: Lunar periodicity of reproduction in the planktonic foraminifer Hastigerina pelagica, Mar. Ecol.-Prog. Ser., 1, 61-64, 1979.

Storz, D., Schulz, H., Waniek, J. J., Schulz-Bull, D. E., and Kučera, M.: Seasonal and interannual variability of the planktic foraminiferal flux in the vicinity of the Azores Current, Deep-Sea Res. Pt. I, 56, 107-124, doi:10.1016/j.dsr.2008.08.009, 2009.

Takahashi, K. and Bé, A. W. H.: Planktonic foraminifera: factors controlling sinking speeds, Deep-Sea Res., 31, 1477-1500, doi:10.1016/0198-0149(84)90083-9, 1984.

Tedesco, K. A. and Thunell, R. C.: Seasonal and interannual variations in planktonic foraminiferal flux and assemblage composition in the Cariaco Basin, Venezuela, J. Foramin. Res., 33, 192210, doi:10.2113/33.3.192, 2003.

Thunell, R. C. and Reynolds, L. A.: Sedimentation of planktonic foraminifera; seasonal changes in species flux in the Panama Basin, Micropaleontology, 30, 243-262, 1984.

Thunell, R. C., Curry, W. B., and Honjo, S.: Seasonal variation in the flux of planktonic foraminifera: time series sediment trap results from the Panama Basin, Earth Planet. Sci. Lett., 64, 44-55, doi:10.1016/0012-821x(83)90051-1, 1983.
Tolderlund, D. S. and Bé, A. W. H.: Seasonal distribution of planktonic foraminifera in the western North Atlantic, Micropaleontology, 17, 297-329, 1971.

Von Gyldenfeldt, A.-B., Carstens, J., and Meincke, J.: Estimation of the catchment area of a sediment trap by means of current meters and foraminiferal tests, Deep-Sea Res. Pt. II, 47, 17011717, 2000.

Wan, S., Jian, Z., Cheng, X., Qiao, P., and Wang, R.: Seasonal variations in planktonic foraminiferal flux and the chemical properties of their shells in the southern South China Sea, Sci. China Earth Sci., 53, 1176-1187, doi:10.1007/s11430-010-4039-3, 2010.

Wolfteich, C. M.: Sattelite-derived sea surface temperature, mesoscale variability, and foraminiferal production in the North Atlantic, M.Sc., MIT and WHOI, Cambridge, MS, 91 pp., 1994.

Žarić, S., Donner, B., Fischer, G., Mulitza, S., and Wefer, G.: Sensitivity of planktic foraminifera to sea surface temperature and export production as derived from sediment trap data, Mar. Micropaleontol., 55, 75-105, 2005.

Žarić, S., Schulz, M., and Mulitza, S.: Global prediction of planktic foraminiferal fluxes from hydrographic and productivity data, Biogeosciences, 3, 187-207, doi:10.5194/bg-3-187-2006, 2006. 